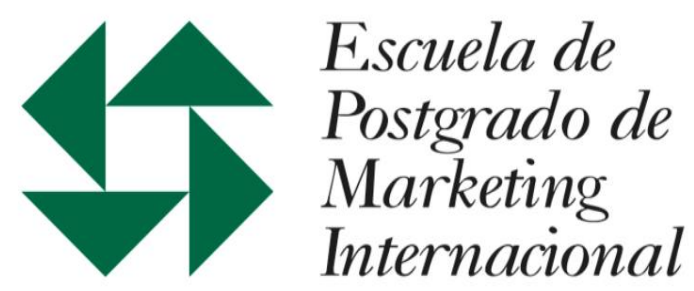

\title{
Diseño y desarrollo de butacas para estadios deportivos: un caso basado en estrategias de marketing y alianzas estratégicas productivas
}

Trabajo Científico libre para la obtención del grado de Magister en Marketing Internacional de la Escuela de Posgrado de Marketing Internacional

Facultad de Ciencias Económicas

- Universidad Nacional de La Plata -

Director de Tesis

Prof. Mg. Federico Del Giorgio Solfa
Presentado por:

Ángel Jesús Alfredo Argüero 


\section{Índice de la tesis:}

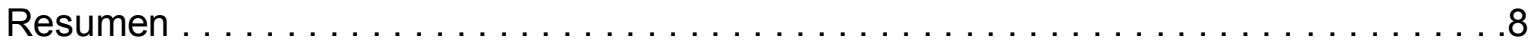

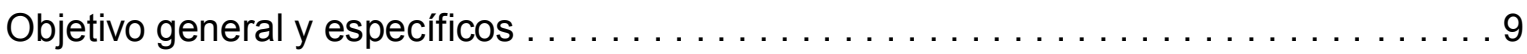

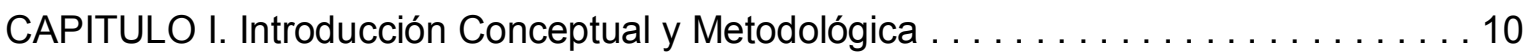

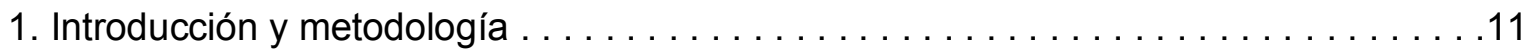

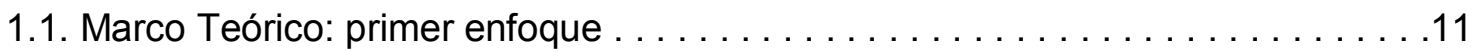

1.2. Marco Teórico: segundo enfoque $\ldots \ldots \ldots \ldots \ldots \ldots \ldots \ldots \ldots \ldots \ldots \ldots \ldots \ldots \ldots \ldots$

CAPITULO II. Necesidad, Oportunidad y Desarrollo Tecnológico. . . . . . . . . . . . 12

2. Contexto específico de la problemática: oportunidad de innovación. . . . . . . . 12

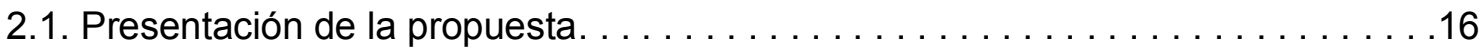

2.2. El proceso de innovación de diseño. $\ldots \ldots \ldots \ldots \ldots \ldots \ldots \ldots \ldots \ldots \ldots \ldots \ldots \ldots \ldots$

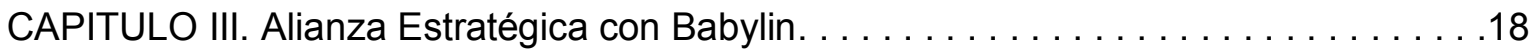

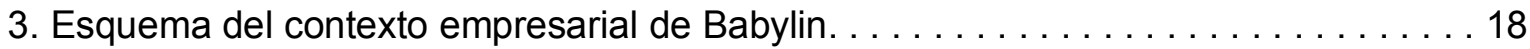

3.1. La Alianza Estratégica. . . . . . . . . . . . . . . . . . . 19

3.2. De las experiencias negativas a la resiliencia. $\ldots \ldots \ldots \ldots \ldots \ldots \ldots \ldots \ldots \ldots$

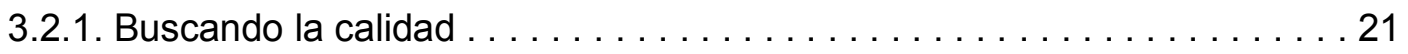

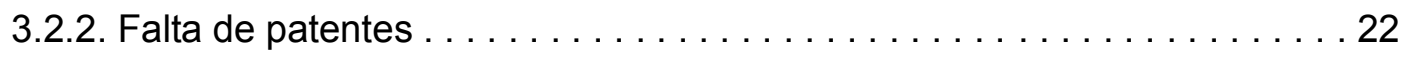

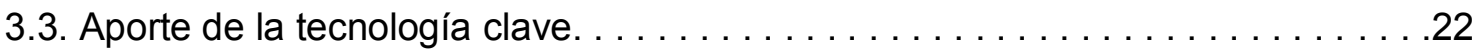

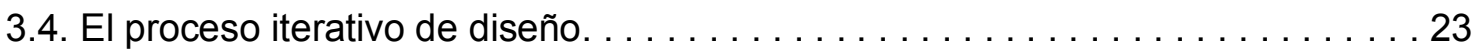

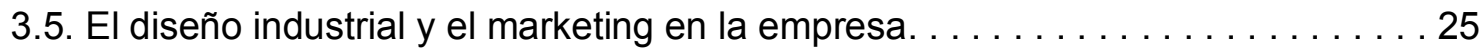

3.5.1. Desde el diseño y el impacto en productos y procesos productivos $\ldots .25$

3.5.2. Desde la organización y la integración del capital humano . . . . . . . 27

CAPITULO IV. Mercados y Competidores. . . . . . . . . . . . . . 29

4. El mercado nacional como primer objetivo. . . . . . . . . . . . . 29

4.1. Globalizando el producto local. . . . . . . . . . . . . . . . . . . . . . . . 31

4.2. Competidores y posicionamientos relativos en el mercado nacional. . . . . . . 33 
4.2.1. Rassegna. . . . . . . . . . . . . . . . . . . . . .

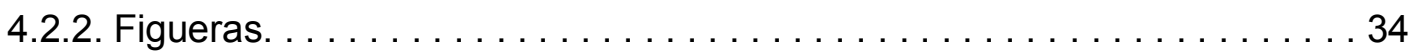

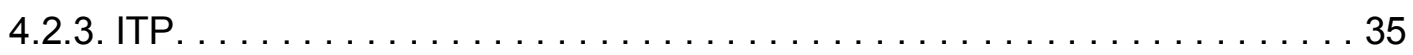

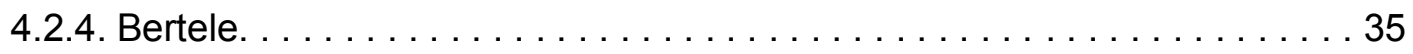

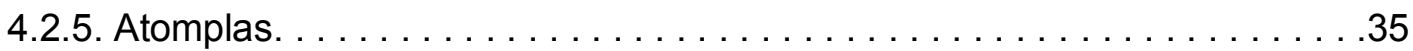

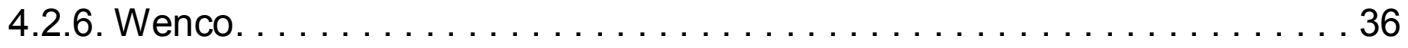

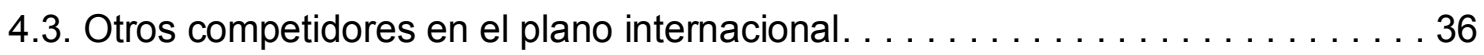

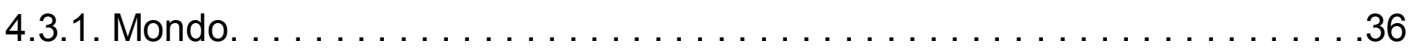

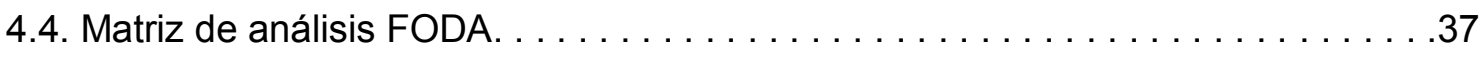

4.4.1. Fortalezas. . . . . . . . . . . . . . . . . . . . . . . . . . .

4.4.2. Debilidades. . . . . . . . . . . . . . . . . . . . . . . . . .37

4.4.3. Amenazas. . . . . . . . . . . . . . . . . . . . . . . .

4.4.4. Oportunidades. . . . . . . . . . . . . . . . . 38

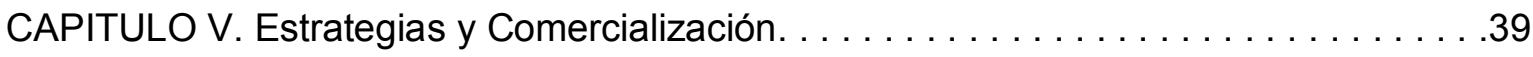

5. Implementación de la Propuesta y Estrategia General. . . . . . . . . . . . 39

5.1. La aplicación del Modelo de Marquis en el proceso. . . . . . . . . . . . . . 40

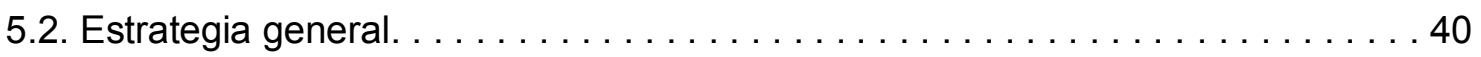

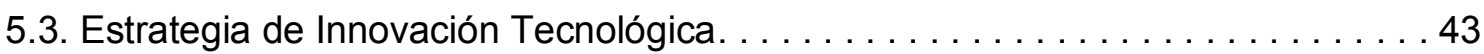

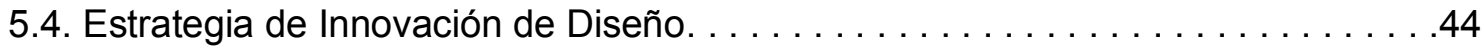

5.4.1. Innovación en forma nuevo producto y de nuevos affordances. . . . . . . 44

5.4.2. Mejora en la calidad de uso del producto. . . . . . . . . . . . .44

5.5. Estrategia corporativa de diseño de marca e isologotipo. . . . . . . . . 45

5.6. Estrategia CKD de Babylin para el $2020 \ldots \ldots \ldots \ldots \ldots . \ldots \ldots$

5.6.1. Beneficios y riesgos. . . . . . . . . . . . . . . 49

5.7. Comercialización del producto e inserción en el mercado. . . . . . . . . . .50

5.7.1. Usos alternativos en la exploración de nuevos segmentos. . . . . . . 52

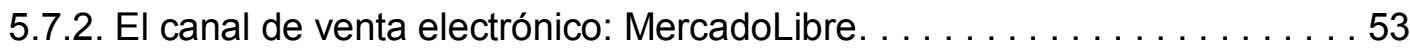

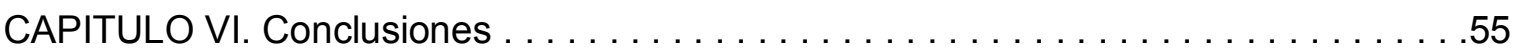




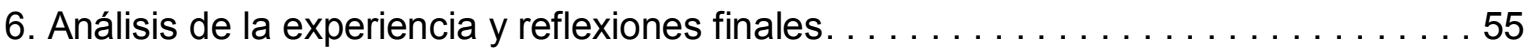

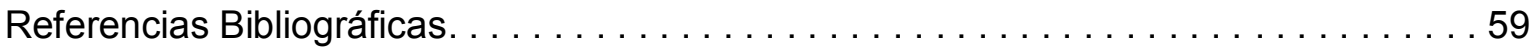

Anexos. . . . . . . . . . . . . . . . . . . . . . . . . . . . . . 61

Anexo 1. Modelo 200 Stadium de Figueras. . . . . . . . . . . . . . . . . . . 61

Anexo 2. Ficha dimensional 200 Stadium. . . . . . . . . . . . . . . . . 65

Anexo 3. Certificado de Ensayo 200 Stadium. . . . . . . . . . . . . . . 66

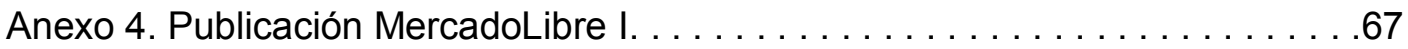

Anexo 5. Publicación MercadoLibre II. . . . . . . . . . . . . . . . . 69

Anexo 6. Estado de Resultados. . . . . . . . . . . . . . . . . . . . . . . .70 


\section{Índice de Figuras}

Figura 1. Esquema y características del rotomoldeado $\ldots \ldots \ldots \ldots \ldots \ldots \ldots \ldots$

Figura 2. Esquema de relaciones de actores en los diferentes contextos. . . . . . . . 20

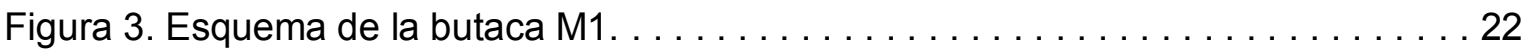

Figura 4. Butacas desarrolladas y producidas en alianza con Babylin. . . . . . . . . . 24

Figura 5. Muestra del resto de las Unidades de Negocio (U.N.) de Babylin. . . . . . . . 29

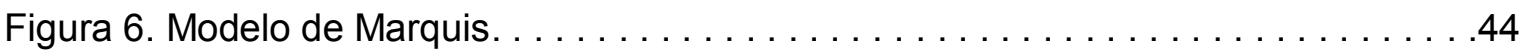

Figura 7. Modelo de estrategia del océano azul. . . . . . . . . . . . . . . . 46

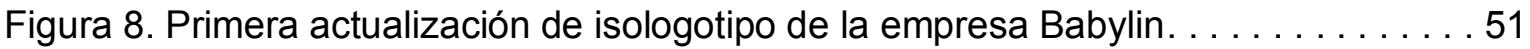

Figura 9. Prueba de color y contraste de la primera actualización de marca . . . . . . . 51

Figura 10. Segunda actualización de isologotipo de la empresa Babylin. . . . . . . 52

Figura 11. Publicación realizada en revista especializada de arquitectura. . . . . . 52

Figura 12. Imagen actual de marca de la empresa Babylin. . . . . . . . . . . . . . . 53

Figura 13. Muestra del M1 y kit de fijación de Babylin aplicado en un kayak. . . . . . . 59

Figura 14. Publicación de M1 de Babylin en Mercado Libre. . . . . . . . . . . . . . .59

Figura 15. Publicación de M1 de Babylin para kayak en Mercado Libre. . . . . . . . . . .60 


\section{Índice de Gráficos}

Gráfico 1. Distribución de los estadios deportivos argentinos. . . . . . . . . . 32

Gráfico 2. Distribución de los estadios deportivos argentinos. . . . . . . . . . 33

Gráfico 3. Mercado argentino de butacas para estadios deportivos. . . . . . . . . . 36 
Índice de Tablas

Tabla 1. Situación de los estadios deportivos en Argentina - Año 2015 . . . . . . . . 34 


\section{Resumen}

El presente trabajo describe una experiencia propia sobre el diseño, desarollo e innovación tecnológica de butacas para estadios deportivos, desde la óptica del Marketing Internacional. Como ejes fundamentales se consideraron: la detección de la necesidad, el aprovechamiento de las oportunidades emergentes y la capitalización del desarrollo tecnológico alcanzado, el análisis de los contextos internos y externos de la empresa Babylin, el reconocimiento de los mercados y la estrategia general. Principalmente se incorpora un proyecto de diseño industrial, basado en la investigación de mercado a partir del requerimiento de un gran proyecto: el Estadio Único "Ciudad de la Plata", en el cuál durante su construcción, se planteo la instalación de butacas deportivas en todas sus tribunas. Por distintos sucesos en el país y por la envergadura del proyecto, se pospuso la adquisición de las butacas. Esta decisión junto a un panorama oscuro en lo económico para el país, dejó al descubierto una oportunidad para el desarrollo del proyecto de butacas. Éste se desarrolló en tiempo record y se implementó la producción de las primeras 500 unidades, luego creció en forma continuada, convirtiendo a una empresa de juguetes en una fábrica de butacas de primer nivel en el país. Esta unidad de negocios, incorporó al diseño industrial y capitalizó las herramientas del Marketing Internacional, que en su formación complementaria el autor de esta tesis encarnaba en el rol de diseñador y gestor tecnológico.

Palabras clave: marketing internacional, diseño y desarrollo de nuevos productos, innovación tecnológica, butacas para estadios deportivos. 


\section{Título de la tesis:}

Diseño y desarrollo de butacas para estadios deportivos: un caso basado en estrategias de marketing y alianzas estratégicas productivas.

\section{Objetivo general:}

Capitalizar los conocimientos del marketing y el diseño industrial en una propuesta sostenible de desarrollo de butacas para estadios deportivos, con posibilidades en mercados locales para insertarse en el mercado internacional.

\section{Objetivos específicos:}

- Identificar las necesidades del mercado local y regional, detectando las oportunidades de desarrollo e innovación tecnológica.

- Estudiar las potenciales alianzas estratégicas productivas para el desarrollo conjunto de tecnologías aplicadas a nuevos productos.

- Analizar los diferentes mercados y competidores para elaborar las principales estrategias corporativas, de innovación de diseño y comercialización.

- Diversificar el producto innovando en productos suplementarios. 


\section{CAPITULO I. Introducción Conceptual y Metodológica.}

\section{Introducción y metodología}

La propuesta es desandar el camino que existe entre la idea y su inserción en el mercado, es decir describir retrospectivamente y de manera sistémica el proceso de marketing y diseño llevado a cabo desde la promoción del proyecto. Para lograr este objetivo, se partióde la propuesta de valor y se analizó la "biografía del producto" hasta llegar a la idea inicial y la estrategia asociada para su implementación.

A través de entrevistas realizadas a diseñadores industriales destacados, se expone el contexto socio- económico en el que tuvo lugar el presente caso de estudio y en el que se desenvolvía el diseño industrial y el marketing. En el primer caso, desde el diseño industrial se señaló que luego de la crisis del 2001-2002, los profesionales del marketing padecieron la coyuntura ya que nadie estaba interesado en marcas, de branding, de packaging diferenciado, y compras en los shopping centers. El valor simbólico se pulverizó de un día para el otro. Los jóvenes diseñadores que ya no encontraban clientes, comenzaron a diseñar productos de baja complejidad tecnológica, algo como un neo-artesanado urbano, colocando los productos en venta en ferias, a precios reducidos porque evitaban los costos de intermediarios.

\subsection{Marco Teórico: primer enfoque}

Para salir de la crisis Argentina del 2001-2002 el sector textil jugó un papel 
importante, pues, a diferencia con el sector automotriz que se caracteriza por un alto grado de concentración, el sector textil presentaba mayor cantidad de ramificaciones capitales. Los diseñadores jóvenes se volcaron al diseño de indumentaria, produciendo en pequeños talleres, casi una industria informal doméstica. Como otra alternativa para sobrevivir, algunos estudios intentaron brindar servicio en el exterior, pues, podían competir mediante el precio. El costo de hora en Argentina era de un tercio del costo internacional de hora diseño. Este proceso, facilitado por la digitalización del internet, hizo que los servicios de diseño comenzaron a ser realizados localmente para clientes de distintos países (Bonsiepe, 2010). ${ }^{1}$

\subsection{Marco Teórico: segundo enfoque}

Hasta hace unos años en Argentina el diseño apenas alcazaba una trayectoria artesanal o semi-industrial con casi ninguna presencia en el mercado. La industria, en la mayoría de los casos, plagiaba el diseño o lo producía bajo el sistema de licencias. Es decir que en mayor o menor grado, Argentina -como gran parte de Sudamérica- fue consumidora de diseño foráneo tanto a través de la importación de manufacturas, como de licencias (Leiro, 2006). ${ }^{2}$

\footnotetext{
${ }^{1}$ BONSIEPE, G. (2010). El Diseño en Tiempos de Turbulencias. Primer Congreso Internacional de Diseño e Innovación de Cataluña.

2 LEIRO, R. (2006). Diseño, Estrategia y Gestión. Ediciones Infinito.
} 


\section{CAPITULO II. Necesidad, Oportunidad y Desarrollo Tecnológico.}

\section{Contexto específico de la problemática:oportunidad de innovación}

El Estadio Ciudad de La Plata, conocido también como Estadio Único, fue inaugurado parcialmente a mediados del 2003. El megaproyecto se terminó de inaugurar en el año 2011 al finalizarse la etapa de techado del estadio, y se llevaba a cabo en un convenio de colaboración junto al Astillero Río Santiago.

Este considerado uno de los estadios deportivos más modernos de Latinoamérica. En el marco de la inauguración parcial del año 2003, se abrió un proceso de concurso de precios a través de una UTE (Unión Transitoria de Empresas), para proveer de las butacas que conformarían los distintos palcos y tribunas del estadio.

Debido a la envergadura del proyecto y a la realidad productiva local de aquel entonces, muchas de las empresas que concursaron eran de origen extranjera y contaban con una capacidad tecnológica elevada.

A pesar de esto, desde la gestión del diseño industrial se asumió el riesgo y se acordó en la UTE la fabricación de 500 unidades, que serían ubicadas en lospalcos preferenciales del Estadio Único, dando a la empresa Rassegna una cantidad de butacas para el resto de las populares.

Este hecho fue determinante, para que desde la gestión de diseño industrial especializada en marketing, se comience a tejer un entramado de alianzas estratégicas que hicieron posible que su producto sea llevado a cabo. Es en este punto donde comienza a ser protagonista el pensamiento estratégico que hizo posible la realización del proyecto. El desarrollo de las 500 unidades implicaba 
una excusa ideal para realizar una prueba de planta piloto, evaluar la rentabilidad del proyecto a largo plazo, realizar ajustes enfocados en la manufactura del producto, y ajustar definitivamente el modelo de negocio como también así, el esquema productivo que hiciera posible la fabricación del producto.

En ese contexto difícil para el diseño industrial local y de manera totalmente autónoma, sin una organización que lo respalde, desde el diseñoindustrial argentino se elaboró una propuesta de diseño que terminó siendo el proyecto final.

A continuación se desarrollan los aspectos principales de la propuesta.

Desde el punto de vista de la concepción, la idea comenzó con lo que en diseño se define como planteamiento de requerimientos de diseño, los cuales fueron claves para guiar la configuración de la propuesta, entre ellos se pueden mencionar:

A. Tecnología clave definida desde el inicio. Se definió el rotomoldeo como un proceso sustitutivo a la inyección de plástico. ${ }^{3}$

\footnotetext{
${ }^{3}$ El rotomoldeo o moldeo rotacional (rotomolding) es un proceso de conformado de productos plásticos en el cuál se introduce un polímero en estado líquido o polvo dentro de un molde y éste, al rotar en dos ejes perpendiculares entre sí (giróscopo), se adhiere a la superficie del molde, generando piezas huecas.
} 


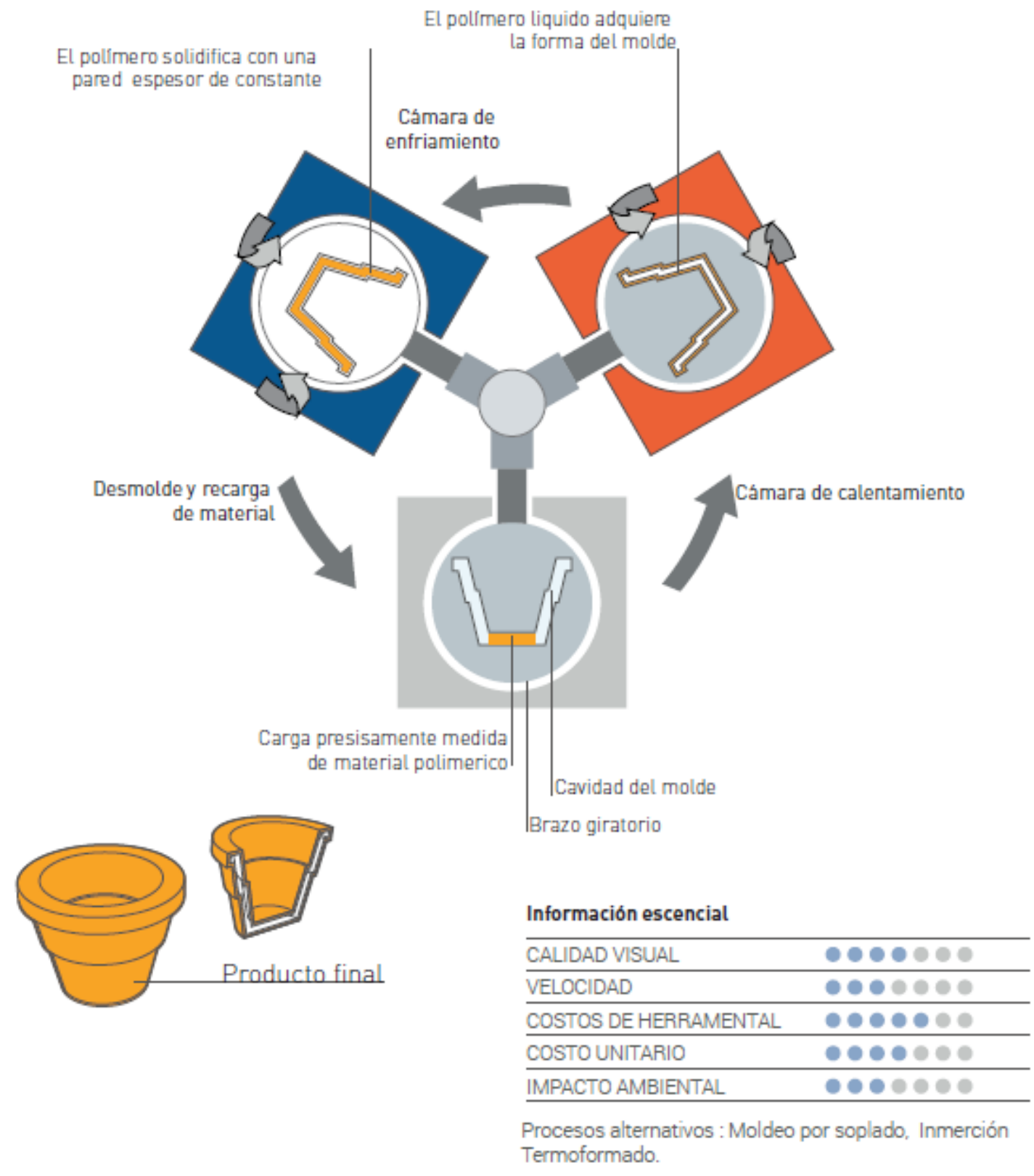

Figura 1. Esquema y características del rotomoldeado.

Fuente: elaboración propia.

B. Aspectos de seguridad y anti-vandalismo. En aquel entonces la seguridad era uno de los aspectos más vulnerables en los eventos futbolísticos. Los conflictos entre "barrabravas", muchas veces incluían 
actos de vandalismo y destrucción de la infraestructura de los estadios, la cual incluye obviamente las butacas de las tribunas.

C. Aspectos ergonómicos y experiencia de uso. Las dimensiones del asiento y el respaldo se encontraban normalizadas, sin embargo al haber definido al rotomoldeo como tecnología clave desde el inicio, se pensó en generar un monovolumen hueco que reemplace a las tradicionales butacas inyectadas de carácter laminar, el cual permitía generar una cámara de aire que además de hacer más confortable a la butaca, actuaba de aislante térmico entre el usuario y las superficies de empotrado, generalmente de hormigón.

D. Mantenimiento. Se pensó desde el inicio en un producto concebido a largo plazo para el cliente. La robustez del monovolumen y la posibilidad de incorporar elementos metálicos de fijación facilitaban su emplazamiento y abría juego a un servicio asociado.

E. Solución como un producto/servicio. Se pensó un producto eficiente a largo plazo. El hecho de pensar en la instalación y la durabilidad, aseguraba a los clientes beneficios económicos a futuro y ayuda a construir una reputación institucional ligada a la responsabilidad e infra-estructura con alto grado de seguridad. 
F. Sustitución de importaciones. Uno de los ejes troncales fue el hecho de plantear un producto que se fabrique con agentes productivos locales (fabricantes, proveedores, recursos humanos, etc.).

\subsection{Presentación de la propuesta}

La presentación de la propuesta se llevó a cabo mediante la realización de un prototipo funcional, generando como resultado un doble impacto: por un lado sorprendió a los profesionales de la UTE conformada por distintas empresas contratadas para la última etapa de construcción del Estadio Único, debido a que se trataba de un producto totalmente diferente al de los competidores, y en otro sentido, generaba incertidumbre el hecho de que desde la gestión de diseño y marketing, no se contaba con el respaldo estructural para dar respuesta a una demanda de tales características.

Frente a la diversidad de marcas competidores, la elección de la UTE centró en buscar un producto diferenciado para la zona VIP. En ese marco, el Modelo M1 de las butacas fue escogido entre el resto de los competidores nacionales e internacionales, por tratarse de un modelo innovador y con una imagen renovada, acorde al momento. El resto de los modelos competidores, estaban desarrollados con diseños similares de los años 80-90s.

\subsection{El proceso de innovación de diseño}

El proceso de innovación en las organizaciones se ha modificado a lo largo de la historia basado en su estado inicial en metodologías fragmentadas lineales y verticalistas en las cuales las decisiones eran tomadas por las áreas gerenciales 
de las empresas, sumado al apoyo del área de I+D (Innovación y Desarrollo), adoptando, a partir de la década de los noventa un enfoque integrador, iterativo y horizontal.

Esto último se hace visible, por ejemplo en el proceso de innovación de quinta generación (modelo de integración de sistemas y establecimiento de redes) el cual incluye la creciente integración tecnológica entre diferentes organizaciones dentro y fuera de la empresa, la forma como estos son reforzados mediante la automatización del proceso de innovación de nuevas técnicas organizacionales, como la ingeniería concurrente, en lugar del desarrollo secuencial (Rothwell, 1994). ${ }^{4}$

\footnotetext{
${ }^{4}$ ROTHWELL, R. (1994). Towards the Fifth-generation Innovation Process. International Marketing Review, Vol. 11 Issue 1, pp. 7-31.
} 


\section{CAPITULO III. Alianza Estratégica con Babylin.}

\section{Esquema del contexto empresarial de Babylin}

Para el proyecto de las butacas, si bien se contaba con el capital cognitivo para proyectar el proceso integral de diseño y fabricación, no se contaba ni con los recursos económicos, ni con la capacidad tecnológica para llevarlo a cabo.

Es aquí donde surge la necesidad de generar alianzas estratégicas complementarias, en la cual se une la empresa con sus capacidades (Strategor 1988, citado por Planellas y Munni, 2014). ${ }^{56}$

En el contexto temporal del inicio de esta alianza, la producción de juguetes era estacional, de acuerdo con las víspera de día del niño (Agosto), Navidad (Diciembre) y Reyes Magos (Enero). Con lo cual, su capacidad oseosa, buscaba integrar nuevos proyectos productivos y encontró en esta unidad de negocios, una nueva oportunidad de desarrollo de mercado.

\footnotetext{
${ }^{5}$ STRATEGOR (1988). Stratégie, Structure, Décision, Identité Ed. Interdictions.

${ }^{6}$ PLANELLAS, M., MUNNI, A. (2015). Las Decisiones Estratégicas. Los 30 modelos más Útiles. Editorial Conecta.
} 


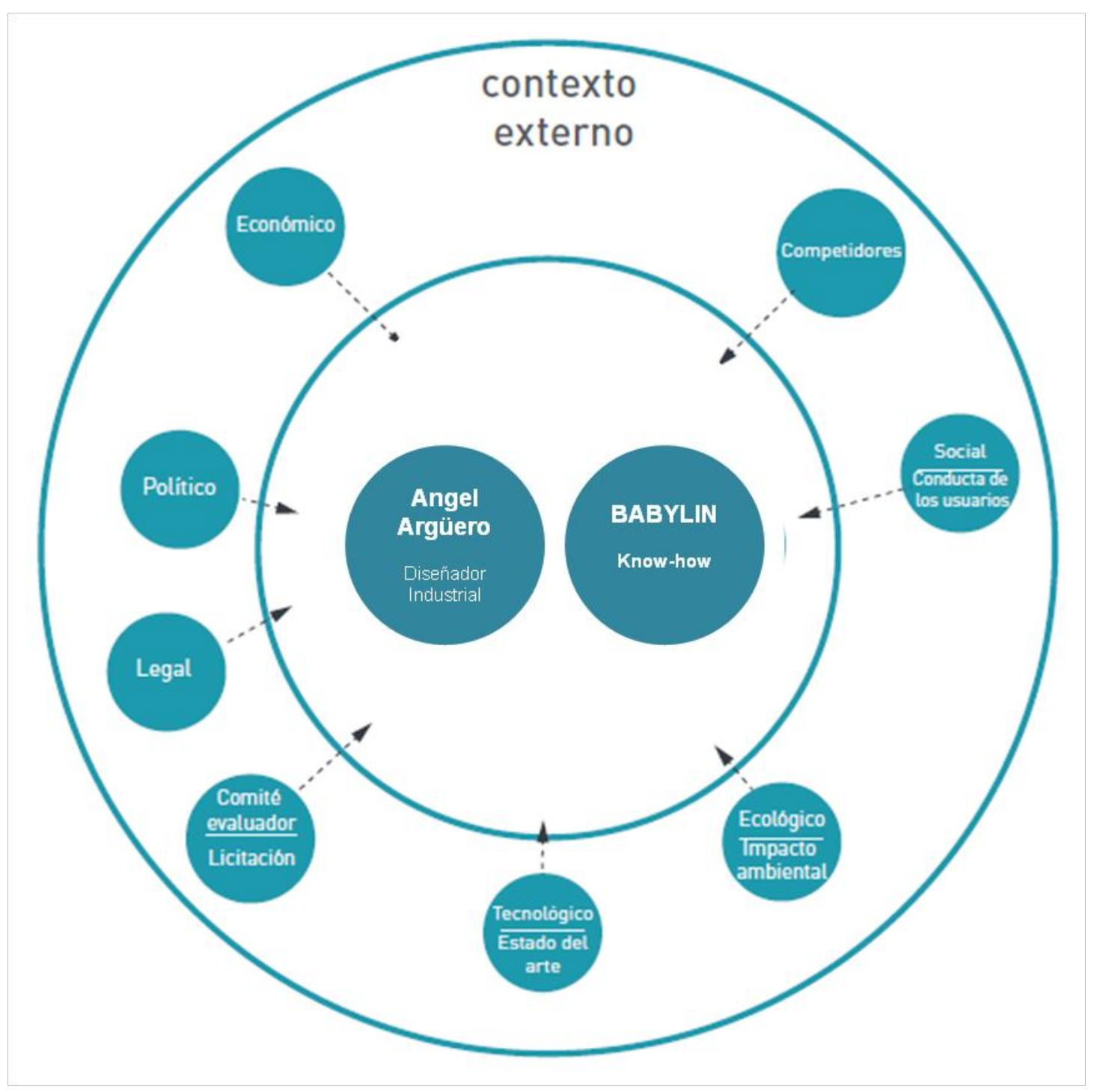

Figura 2. Esquema de relaciones de actores en los diferentes contextos.

Fuente: elaboración propia.

\subsection{La Alianza Estratégica}

En la alianza estratégica entran en juego una serie de actores claves que conformaron el esquema productivo y dieron lugar a una organización híbrida y colaborativa. En el caso de estudio abordado a través de la denominada butaca M1 (ver Figura 1), la idea surge a partir de la detección de una necesidad de mercado (market-pull), si bien el disparador fue el proceso de licitación del estadio Ciudad de La Plata que generó una demanda puntual, el hecho de que el 
diseñador industrial contara con una formación enfocada en el campo de la gestión y marketing, sumado al conocimiento teórico-práctico de las herramientas tecnológicas, dio como resultado una visión ampliada de la oportunidad de negocio y el potencial expansivo futuro que ésta llevaba asociado.
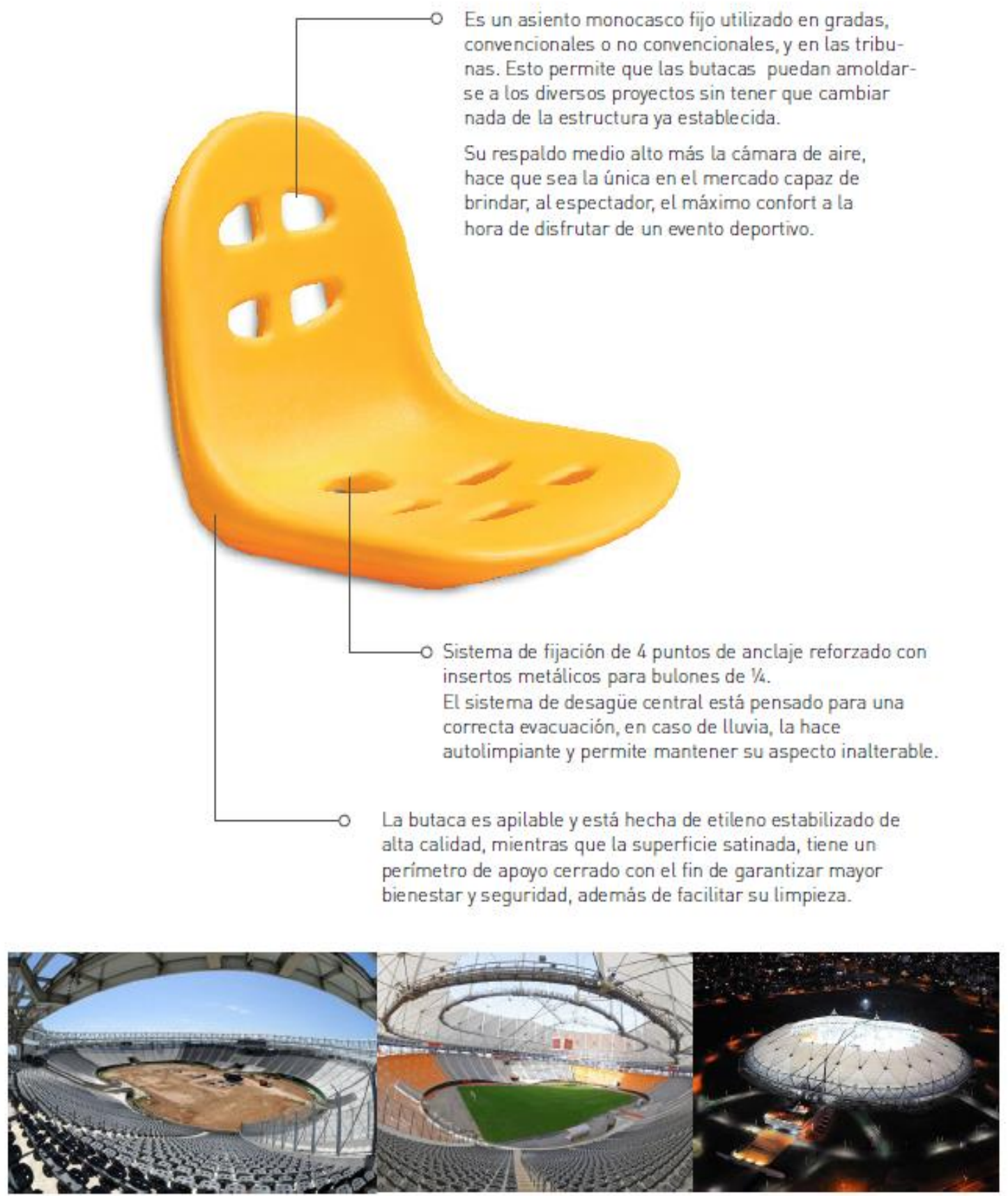

Figura 3. Esquema de la butaca M1.

Fuente: elaboración propia. 
La experiencia negativa ligada a la falta de protección industrial, y a pesar de que el sistema de registros y patentes en el país no funciona con el rigor adecuado, se procedió al registro del modelo industrial para proteger la idea.

La búsqueda siguió y dio un viraje estratégico. Desde la gestión del diseño industrial se redefinieron los criterios de selección de la empresa productora y definió el siguiente requerimiento basado en la calidad: se necesitaba una empresa con know-how incorporado, que desarrollara productos con alta complejidad tecnológica, flexible en cuanto a la escala productiva, que asegurara la mayor calidad de producto, y grados de terminación diferenciales.

Este requerimiento llevó a pensar en proveedores de servicios de sectores industriales que demanden especificaciones técnicas concretas y trabajen bajo normalizaciones y estándares de calidad.

Es aquí donde se pensó de manera asociativa en la industria del juguete. Este sector industrial se rige por un sinnúmero de normativas debido a las características del usuario específico. Luego de esta decisión estratégica,toma relevancia la empresa Babylin, dedicada a la fabricación de juguetes y productos especiales, con la cual se mantiene la alianza hasta la actualidad.

\subsection{De las experiencias negativas a la resiliencia}

\subsubsection{Buscando la calidad}

Esta alianza se lleva a cabo buscando proveedores que aseguraran calidad sostenida en el tiempo, para ello, luego de un proceso de búsqueda y desarrollo, se logró establecer Fundición EME (Establecimiento Metalúrgico Ensenada) como 
proveedor del servicio de fundición de aluminio para la fabricación de la matricera del producto, la cual contaba con materias primas, de buena calidad y una experiencia de trabajos muy fuerte más de 30 años. En el caso del material polimérico que conforma la butaca, se continuó trabajando con el proveedor que asistía a la empresa debido a la calidad de producto y asesoramiento que suministraba.

\subsubsection{Falta de patentes}

El proceso fue arduo, ya que en el camino hubo competencia desleal, debido a que el producto no gozaba de protección industrial (patente), esto posibilitó que una de las empresas con las que se buscó generar la alianza comercialice el producto por su cuenta.

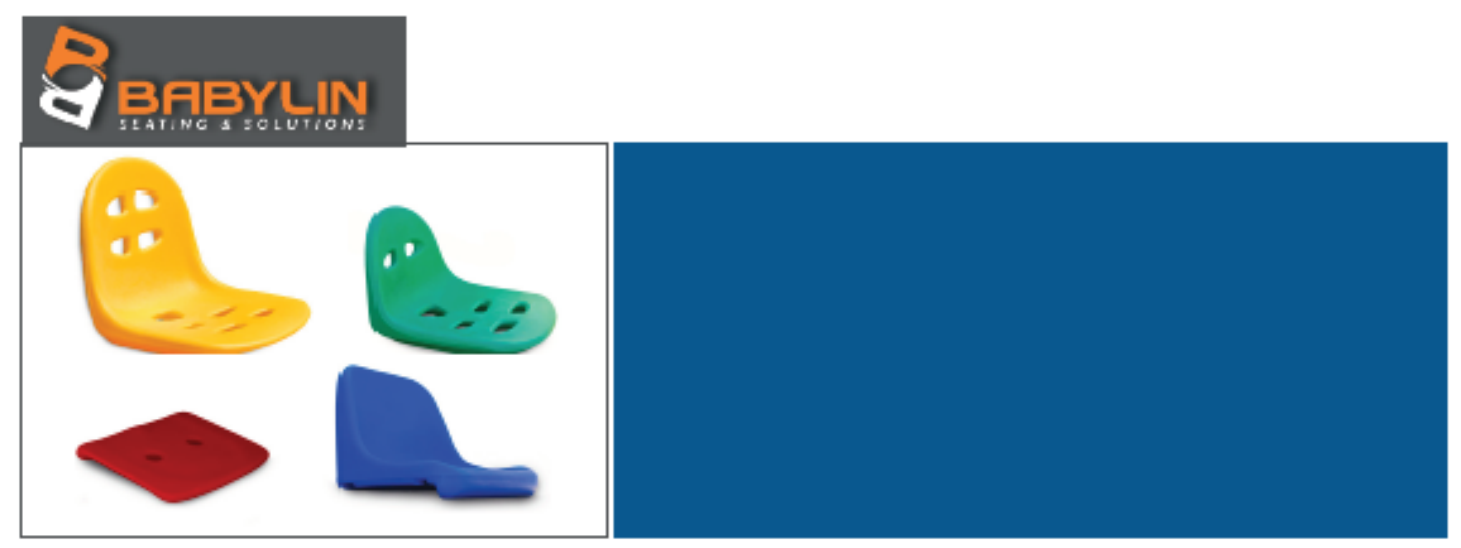

Figura 4. Butacas desarrolladas y producidas en alianza con Babylin.

\subsection{Aporte de la tecnología clave}

Las tecnologías clave según A.D. Little (1981) son las que permiten a la empresa que las domina diferenciarse de las otras por su mayor calidad, prestaciones 
superiores, costos más bajos, etc. Son, por tanto, las que tienen un impacto más

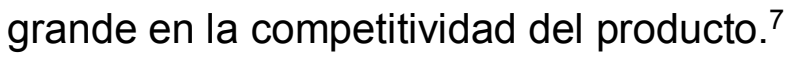

Generalmente, se tiene una concepción lineal de los avances tecnológicos, y parecen ser concebidos como un encadenamiento de superaciones acumulativas en donde las nuevas tecnologías dejan obsoletas a las tecnologías anteriores. Sin embargo, en el presente caso de estudio se demuestra que una tecnología que parecía en desuso en ciertos segmentos de mercado y que connotaba un índice de productividad inferior, respecto a tecnologías más avanzadas, como es el caso de la inyección, logró dar un aporte en un contexto específico a la problemática de diseño.

Esto, nos recuerda una vez más, que no existen soluciones estandarizadas de diseño y cada problema merece un análisis multidimensional del ecosistema en el que está inmerso.

\subsection{El proceso iterativo de diseño}

Si se analiza la naturaleza del proceso de innovación se puede ver que responde al modelo de innovación de Marquis (1969), el cual pone a la idea como motor fundamental de las innovaciones, partiendo de una idea de un nuevo o mejor producto o proceso de producción. ${ }^{8}$

Si bien la empresa Babylin provenía de un nicho tecnológico definido, como es el caso del rotomoldeo, el diseñador industrial logró insertarlo en una industria sin

\footnotetext{
${ }^{7}$ LITTLE, A. D. (1981). The Strategic Management of Technology. Cambridge, Massachusetts.

${ }^{8}$ MARQUIS, D. G. (1969). The Anatomy of Successful Innovations. National Science Foundation, Technical Report, Vol. 69.
} 
antecedentes y capitalizar todo el know-how con el que contaba la empresa para posicionarlo en un nuevo segmento de mercado.

Es en este sentido que se puede reivindicar la función del diseñador industrial como promotor de la innovación tecnológica. Referido a este rol de articulador de elementos aparentemente disímiles, M. Chiapponi (1999) plantea las distintas maneras en las que el diseñador puede ser un agente clave de este proceso de innovación. ${ }^{9}$

En esta dirección, sostiene que una de las tipologías innovadoras en las que el diseño industrial está en grado de expresar con mayor fuerza su propio potencial es la de las diversas formas de innovación por transferencia y por fecundación transversal: innovación mediante imitación, transferencia de innovaciones de un sector productivo a otro, transferencia de las grandes empresas medianas y pequeñas de lo inducido y viceversa, transferencia de instrumentos altamente especializados para uso profesional a los correspondientes enseres para uso cotidiano.

Asimismo, Chiapponi (1999) explica que algunas innovaciones se propagan al mismo tiempo en diversos sectores. A menudo una gran innovación en un sector puede estar determinada por la transferencia de ideas y soluciones provenientes de otro campo en el que las mismas ideas y soluciones ya no son innovadoras sino también plenamente adoptadas desde largo tiempo. ${ }^{10}$

En todos estos casos el diseño industrial, por su natural propensión a trabajar por asociaciones, en modo transversal, puede contribuir en gran medida en los

\footnotetext{
${ }^{9}$ CHIAPPONI, M. (1999). Cultura Social del Producto. Editorial Infinito.

${ }^{10}$ Ibídem.
} 
procesos de innovación creando cruzamientos con métodos que pueden compararse con la polinización. ${ }^{11}$

Ahora bien, lograr esta adaptación tecnológica para lograr competitividad, no fue una tarea fácil. Además de representar un reto intelectual para el diseñador industrial desde el punto de vista tecno-productivo, implicaba un desafío comunicativo para lograr de alguna manera modificar ciertos hábitos y rutinas propias de la dinámica interna de la empresa, acostumbrada a procesos más tradicionales y con la miopía proyectual que generanlas actividades del día a día en este tipo de organizaciones.

\subsection{El diseño industrial y el marketing en la empresa}

Se propone abordar este vínculo desde dos perspectivas, detalladas a continuación.

\subsubsection{Desde el diseño y el impacto en productos y procesos productivos}

Para la primera perspectiva el ingreso del diseñador industrial a la empresa, permite extraer algunas conclusiones, e incluso ciertas contradicciones sobre los efectos que genera en su dinámica productiva.

Si se analiza desde el punto de vista comercial, esto permitió optimizaciones en procesos productivos que serán transferibles a cualquiera de los productos, se

\footnotetext{
${ }^{11}$ La polinización es el proceso que se desarrolla desde que el polen deja su lugar hasta que llega al lugar de germinación. Esta analogía, por lo tanto, ubica al diseño industrial como el agente que permite la germinación de ideas e innovación y contribuye a la aparición de nuevos frutos y semillas productivas.
} 
logró diversificar la cartera de productos de Babylin e inclusive se mejoraron productos que ya comercializaba:

La cartera de productos fue diversificada a través de los distintos modelos de butacas y accesorios para kayak y destinos comerciales alternativos.

Respecto a la mejora de productos, se transfirieron los conocimientos adquiridos en el proceso al juguete mecedor (caballito) y mobiliario para niños (mesa y silla), resolviendo los requerimientos técnicos en cuanto a esfuerzos y fatigas.

Ahora bien, esto puso en evidencia la importancia de que haya coherencia entre la estrategia general de la empresa y la estrategia tecnológica y comercial.

Lo que ocurrió en el caso de Babylin, es que esta nueva unidad de negocio (butacas) tenía tal grado de desarrollo que generaba cierto contraste con los productos que venía comercializando la empresa. A pesar de que la empresa sigue posicionada perfectamente en ambos sectores (juguetes y butacas) se puede percibir en su sitio web un cierto desfasaje tecnológico entre ellos.

Es importante tener presente esta base conceptual, ya que el enfoque que se llevó a cabo desde el diseño industrial para poner en marcha el proceso de fabricación fue enfocado en la gestión de marketing, la cual comprende el conjunto de actividades de diagnóstico, coordinación, comunicación, negociación y diseño que se llevan a cabo interactuando con la empresa. 


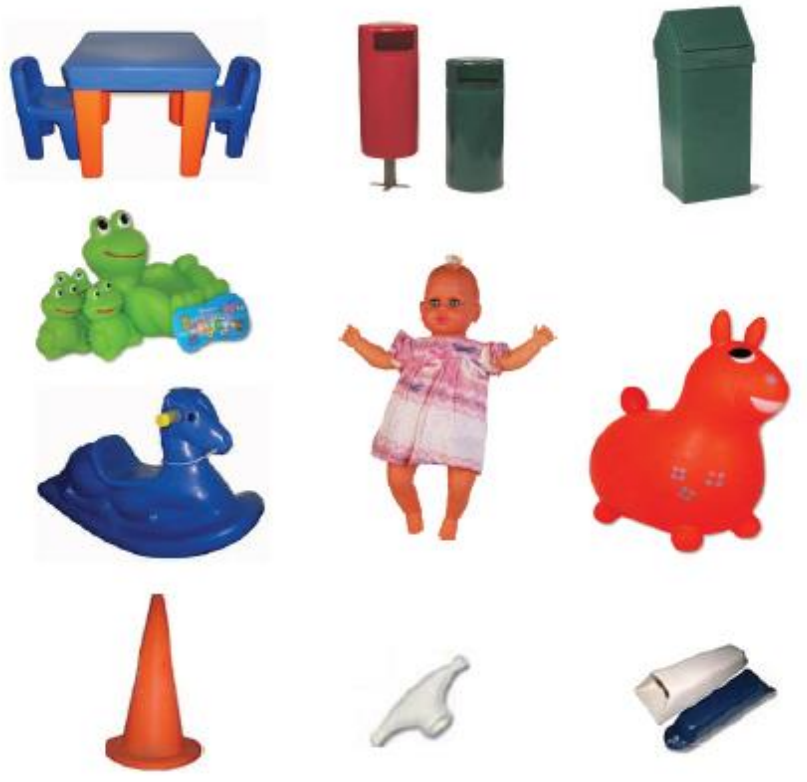

Figura 5. Muestra del resto de las Unidades de Negocio (U.N.) de Babylin.

\subsubsection{Desde la organización y la integración del capital humano}

El caso de estudio, de algún modo ilustra el vínculo que se establece muchas veces entre el diseñador industrial como agente externo y la empresa responsable del proyecto.

Si bien este modo de operar no es el ideal para lograr procesos de innovación y promover la mejora continua dentro de la empresa, en el contexto de la industria local, las empresas todavía no han tomado conciencia de la importancia de establecer un departamento de diseño permanente que forme parte del equipo estable de la misma.

A pesar de este vínculo temporal, entre el diseñador industrial y la empresa, lograr un trabajo en conjunto implica un gran desafío para ambas partes, dando lugar a un intercambio muy enriquecedor. 
Por un lado, la mirada externa del diseñador industrial, poseedor de un conocimiento codificado y por otro el bagaje técnico propio del oficio que posee el recurso humano de la organización (conocimiento tácito) da lugar a nuevas maneras de hacer y de algún modo redefinen los modos operativos de estos grupos.

El diseñador debe lograr acoplarse a la vida propia de la empresa, debe hacer concesiones y adaptar soluciones para maximizar los recursos con los que dispone.

Esta integración del diseño a la manufactura es la que genera en definitiva que una idea se materialice y es sin duda responsabilidad del diseñador abordarla. Algunos de los aspectos que consideramos fundamentales para que la alianza aún se mantenga vigente son la horizontalidad en la toma de decisiones (todas las decisiones se votan entre los miembros de la empresa), el diálogo constante entre los miembros de la organización, la identificación de roles claros dentro del equipo de trabajo, la libertad para proponer ideas de nuevos productos (siguiendo con el modelo de Marquis, 1969) y los objetivos compartidos que se plantean como organización lo cual hace que los riesgos sean compartidos. ${ }^{12}$

\footnotetext{
${ }^{12}$ MARQUIS, D. G. (1969). The Anatomy of Successful Innovations. National Science Foundation, Technical Report, Vol. 69.
} 


\section{CAPITULO IV. Mercados y Competidores.}

\section{El mercado nacional como primer objetivo}

El mercado argentino de butacas para estadios deportivos es muy pequeño, comparado con el de los grandes países de Latinoamérica como Brasil, y México.

Desde el punto de vista escalar, según conjeturas realizadas en el año 2015 del entorno del mercado para los mercados de este tipo de producto, encontramos que las categorías según país se dividen en: gran mercado, mediano, pequeño y específicos (AFA y Estadios de Argentina, 2015). ${ }^{13}$

Gráfico 1.Distribución de los estadios deportivos argentinos.

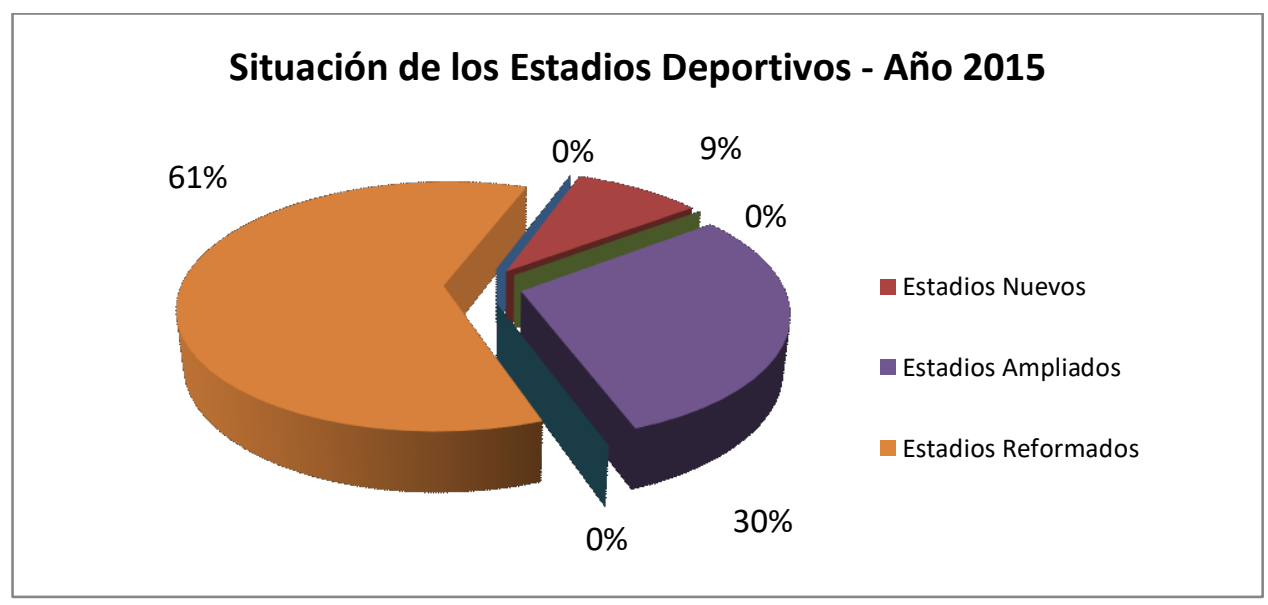

Fuente: elaboración propia en base a datos relevados de AFA y Estadios de Argentina. Sitios Web: http://www.afa.org.ar ; http://www.estadiosdeargentina.com.ar

En esta lógica, Argentina se encuadra en la categoría depequeño mercado, porque la infraestructura de estadios deportivos, si bien es escasa y necesaria,es costosa.

\footnotetext{
${ }^{13}$ AFA y Estadios de Argentina (2015). Sitios Web: http://www.afa.org.ar ; http://www.estadiosdeargentina.com.ar
} 
Por otro lado, debemos entender la dimensión "intelectual", de algunas acciones de infraestructura deportiva en el ámbito de la provincia de Buenos Aires, que llevaron al fracaso de su aplicación.

Este es el caso del Estadio Único de La Plata, que en su concepción como único estadio no pudo ser, ya que los clubes locales no podían tener un estadio sin pertenencia alguna. Por este motivo, los clubes platenses: Estudiantes y Gimnasia y Esgrima, llevaron adelante remodelaciones de sus antiguos estadios.

Es así como emerge lo que realmente sucede, no se crean nuevos clubes de futbol, sino que son los históricos de siempre, y pocos son los que han podido readecuar o iniciar nuevas obrasparasus estadios.

Gráfico 2. Distribución de los estadios deportivos argentinos.

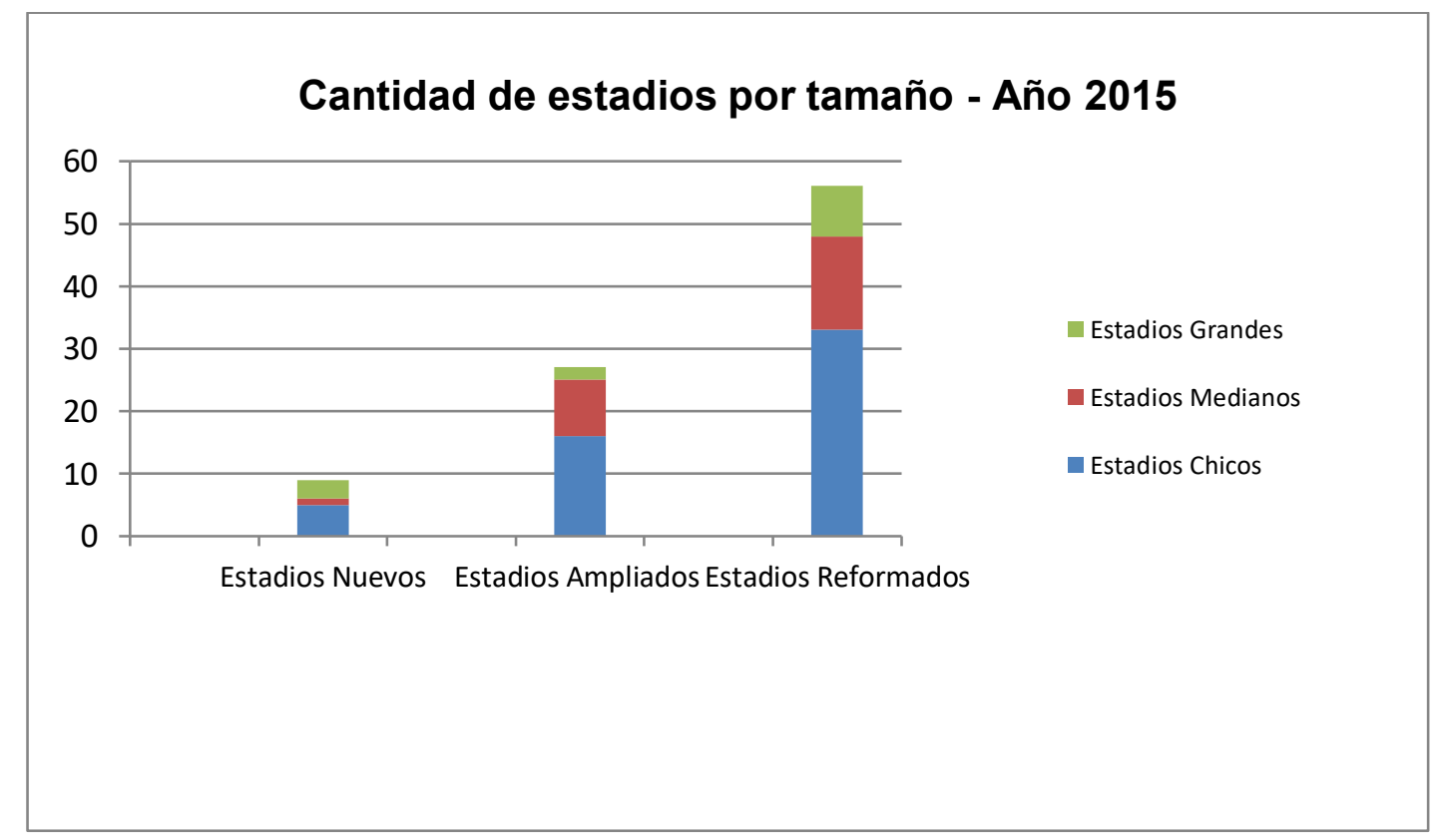

Fuente: elaboración propia en base a datos relevados de AFA y Estadios de Argentina. Sitios Web: http://www.afa.org.ar ; http://www.estadiosdeargentina.com.ar 
Por lo tanto, notamos, que se mantiene un promedio anual de entre 2 a 5 estadios, como proyectos importantes. Lógicamente, de la más variada magnitud: grandes, medianas o pequeñas obras de infraestructura.

Tabla 1. Situación de los estadios deportivos en Argentina - Año 2015

\begin{tabular}{lrrrr}
\hline \multicolumn{5}{c}{ Tipos de Estadios } \\
\hline Situación & Pequeños & Medianos & Grandes & Globales \\
\hline Nuevos & 5 & 1 & 3 & 9 \\
Ampliados & 16 & 9 & 2 & 27 \\
Reformados & 33 & 15 & 8 & 56 \\
Totales & 54 & 25 & 13 & 92 \\
\hline
\end{tabular}

Fuente: elaboración propia en base a datos recolectados a través de AFA, ACA, Liga Nacional de Básquet y Clubes. Corresponde a clubes de futbol, barriales, de básquet, autódromos e hipódromos.

La mayoría de los clientes se ubican en tres lugares,losmás importantes se encuentran en la provincia de Buenos Aires y Capital Federal (CABA).

\subsection{Globalizando el producto local}

Según lo relevado por el autor en los mercados internacionales, prevalece la presencia de empresas españolas, alemanas, mexicanas, chinas, italianas, norteamericanas y polacas.

En este contexto, consideramos que la experiencia de Babylin representa una localización regional de un producto local, en vías de exportación (incipiente) a países latinoamericanos (París, 2009). ${ }^{14}$

${ }^{14}$ PARÍS, J. A. (2009). Marketing esencial, un enfoque latinoamericano. Errepar, Buenos Aires. 
Debido a su naturaleza empresarial, Babylin no posee una "gran espalda" económico-financiera, motivo por el cual, la "llegada fuerte" a los países vecinos está demorada.

Por otro lado, entendemos que las características técnicas de las butacas M1 son ampliamente superiores al resto de sus competidores. Principalmente, debido al diseño y características técnicas de limpieza y durabilidad en el uso.

Desde el plano empresarial, se cuenta con una solvente experiencia, no solo en la fabricación, sino también en el hecho de haber: realizado ensayos, comprobaciones de mercado, alcanzado altos volúmenes de venta, efectuado servicios de instalación;aprendido de los consumidores alrealizar las mejoras sugeridas, comprendido en el tiempo sobre las virtudes del producto, sostenido una postventa considerable que permitió consolidar un fuerte vínculo con los clientes, aún habiendo cambiado las personas de contacto en los distintos clubes. Al tener investigación y desarrollo propia (I+D), permitió además incorporar la innovación tecnológica al proceso $(I+D+I)$.

A partir de esta característica, se realizaron soluciones a medida en productos acotados, logrando aprender de los clientes y al mismo tiempo descubrirnuevos nichos de mercado, como por ejemplo con el segmento de los clubes de básquet de la liga nacional, a los cuales hoy se les está desarrollando algunos productos específicos (París, 2014). ${ }^{15}$

${ }^{15}$ PARÍS, J. A. (2014). Los cuatro aspectos esenciales por investigar. Poliantea, 10(18), pp. 65-81. 


\subsection{Competidores y posicionamientos relativos en el mercado nacional}

En la actualidad, a través de una estimación propia, tenemos que el $97 \%$ del mercado nacional de butacas para estadios deportivos, se satisface en base a seis marcas principales: Babylin (42\%), Rassegna (17\%), Figueras (10\%), Bertele (10\%), ITP (10\%) y Wenco (4\%). ${ }^{16}$

Gráfico 3. Mercado argentino de butacas para estadios deportivos.

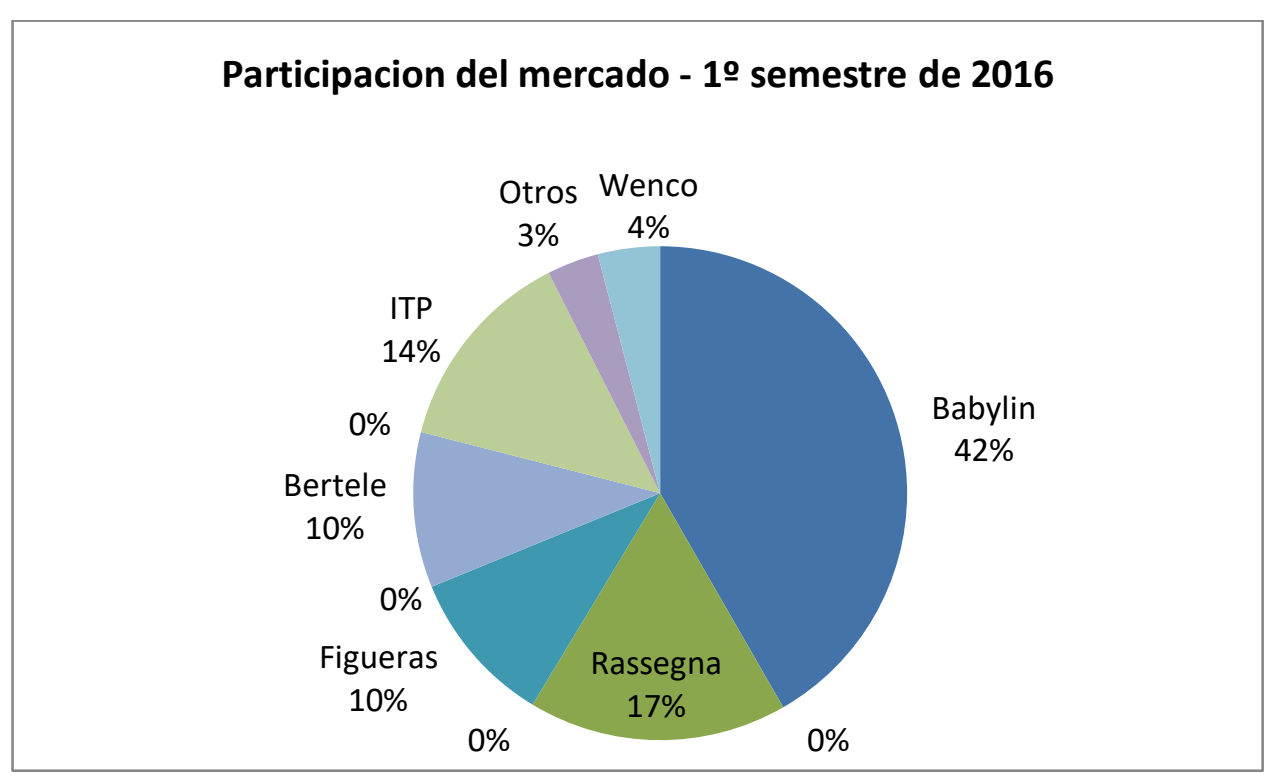

Fuente: elaboración propia en base a relevamientos y experiencia de mercado.

\subsubsection{Rassegna}
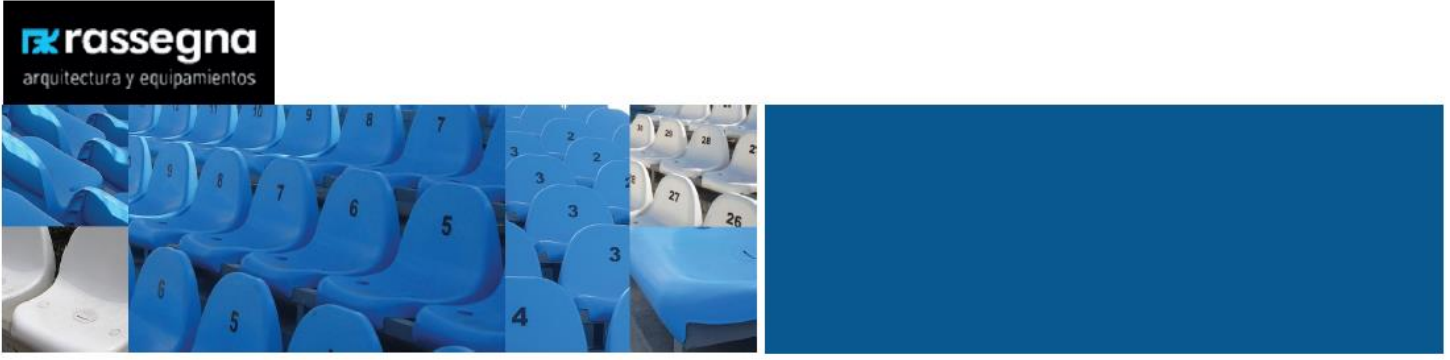

${ }^{16}$ Relevamiento propio de butacas en estadios deportivos nuevos de gran escala (2016). 
Rassegna es una empresa ubicada en la Ciudad Autónoma de Buenos Aires, fundada en 1985 y posicionada como fabricante de asientos para estadios, teatros, anfiteatros y otros. ${ }^{17}$

La tecnología empleada por Rassegna es el plástico inyectado. Ofrece butacas para estadios deportivos obsoletas (asiento PL7) y como posee una matriz ya muy amortizada, sus productos se posicionan por bajo costo.

Es por ello, que sus productos no cuentan con un diseño competitivo, ni poseen prestaciones adecuadas a los estándares vigentes.

\subsubsection{Figueras}

\section{FIGUERAPS}
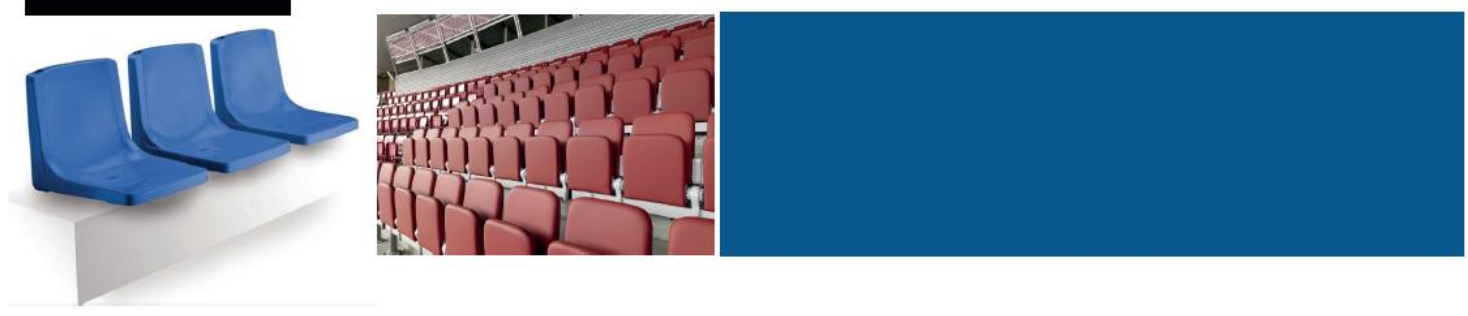

Figueras International Seating, fundada en Barcelona (España) en 1929, posee oficinas en más de cinco países y está enfocada en el mercado internacional. Su tecnología clave es la inyección de plástico. Esta multinacional española es la empresa $\mathrm{N}^{\circ} 1$ en el mundo, por su amplia variedad de productos y posee el antecedente comercial de haber abastecido a grandes obras emblemáticas. ${ }^{18}$ Actualmente, posee el modelo 200 Stadium, un asiento deportivo de una sola pieza, pero no tiene un producto competitivo como el de Babylin en el mercado.

\footnotetext{
17 Sitio Web: http://www.rassegna.com.ar/productos/

${ }^{18}$ Sitio Web: http://www.figueras.com/es/
} 
En el año 2015, se entabló un acercamiento comercial, por el cual Babylin cubriría un segmento del mercado que ellos no habían desarrollado, el segmento de butacas de bajo costo desarrollada para terceros países (Ibídem).

\subsubsection{ITP}

Esta es una empresa que plagió el modelo M1 de las butacas de Babylin, no tiene estándares ni códigos y sus productos se basan en la inyección. El principal problema que presenta, es la bastardización que hacen del producto. No puede satisfacer altos volúmenes de venta, como si lo hace el producto desarrollado por Babylin. En cuanto a la calidad, no alcanza los estándares de ningún tipo.

\subsubsection{Bertele}

Es una empresa italiana con representación comercial local, tiene solo contactos con personas del ejecutivo de la AFA, las cuales ejercen presión de lobby. No tiene respaldo comercial. ${ }^{19}$

\subsubsection{Atomplast}
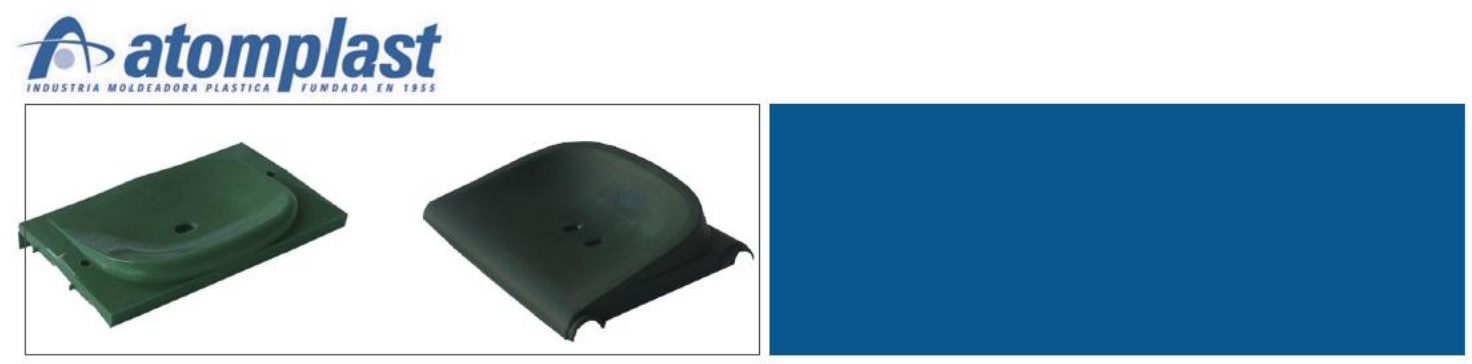

${ }^{19}$ Sitio Web: http://bertele.com/seat.php?lingua=en 
Esta empresa, tiene un solo tipo de butacas, llamado comúnmente "butaquín" ya que es un asiento sin respaldo y morfológicamente con muy bajo perfil, sin altura. $^{20}$

\subsubsection{Wenco}

Es un fabricante de butacas de baja escala de serie,posee una matriz anticuada y tiene poca incidencia en el mercado, las principales unidades de negocios de la empresase basan en otros productos. ${ }^{21}$

\subsection{Otros competidores en el plano internacional}

\subsubsection{Mondo}

\section{IIIMHONDO}
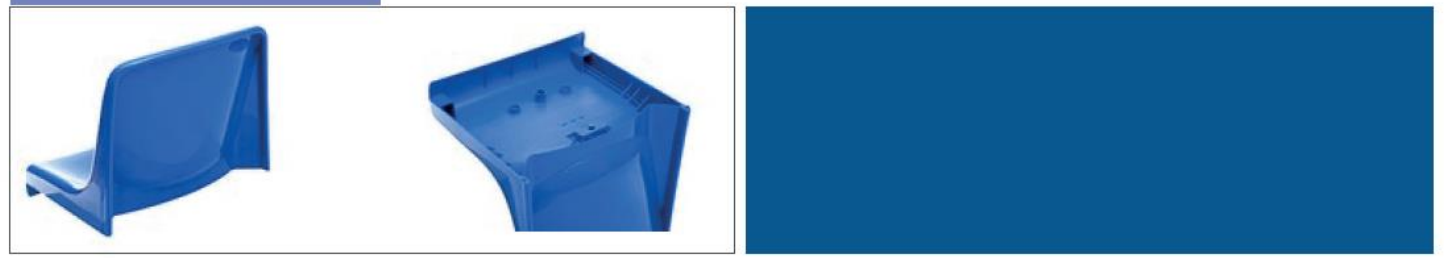

Es una marca de Venelli Seating ${ }^{22}$, empresa fundada en 1958. Venelli es líder mundial en el diseño y fabricación de asientos para instalaciones recreativas y deportivas cubiertas y al aire libre.

\footnotetext{
${ }^{20}$ Sitio Web: http://www.atomplast.com.ar/

${ }^{21}$ Sitio Web: http://wenco.com.ar/

${ }^{22}$ Sitio Web: http://www.venelliseating.com
} 
Los sistemas de asientos Venelli, han sido instalados en más de 60 países en todo el mundo, desde el Estadio Olímpico de Roma hasta el Circuito de Sepang en Malasia. La tecnología clave utilizada, es la inyección de plástico.

\subsection{Matriz de análisis FODA}

\subsubsection{Fortalezas:}

- Producto diseñado exclusivamente para el mercado latinoamericano.

- Versatilidad para modificaciones en el producto con bajo costo.

- Uso de tecnología conocida, aggiornada a la actualidad.

- Variedad de instalación: con o sin estructura.

- Variedad de colores en cualquier cantidad.

- Optima resistencia al vandalismo.

- Significancia del producto.

- No depende de estructura para su instalación.

- Insertos metálicos ofrecen seguridad de fijación.

- Servicio postventa único en el país.

- Garantía de 5 años por defectos de fabricación.

\subsubsection{Debilidades:}

- No puede competir con la inyección de plástico.

- Producto fácilmente plagiable (copiable). 
- Marco jurídico no obedece los tiempos de obra.

- Segmento de mercado muy politizado.

- Alta incobrabilidad.

- Estudios de arquitectura sin información técnica del producto.

\subsubsection{Amenazas:}

- Importación de butacas de China y Europa, preferentemente.

- Facilidades comerciales para la importación (Gobierno Nacional).

- Liberación de las cláusulas DD.JJ.

- Villa olímpica ya proyectada con butacas importadas.

- Exportaciones desde argentina al mundo, difícil de cumplir por la burocracia de cumplimentaciones, donde en algunos casos estamos exentos pero igual requiere presentación de mucha documentación contable y ambiental con alto costo de consultoría y sellados de Colegios Profesionales.

\subsubsection{Oportunidades:}

- Visión de los nuevos canales comerciales.

- Nuevos modos de comercialización.

- Presencia en el exterior a través de redes sociales.

- Especial atención a subas (o disparadas) desmedidas del dólar.

- Créditos para clubes con mayores tiempos de pago. 


\section{CAPITULO V. Estrategias y Comercialización.}

\section{Implementación de la Propuesta y Estrategia General}

Se puede decir que la estrategia del diseñador abordó diferentes dominios, indicados a continuación.

Como ya lo anticipamos, el modelo de Marquis adoptado, es que propone que la idea puede provenir de cualquier área de la organización, no sólo del departamento de I+D. Son tenidas en cuenta las opiniones de los clientes y demandas del mercado y la idea debe cumplir con dos requisitos fundamentales: factibilidad técnica y demanda potencial. ${ }^{23}$

A partir de la idea central se pone en marcha un proceso iterativo que examina las posibilidades de la tecnología actual (estado del arte) y si ésta no cumple los requerimientos, se puede hacer uso de la investigación aplicada e inclusive de la investigación básica (Marquis, 1969). ${ }^{24}$

\subsection{La aplicación del Modelo de Marquis en el proceso}

\footnotetext{
${ }^{23}$ MARQUIS, D. G. (1969). The Anatomy of Successful Innovations. National Science Foundation, Technical Report, Vol. 69.

${ }^{24}$ Ibídem.
} 


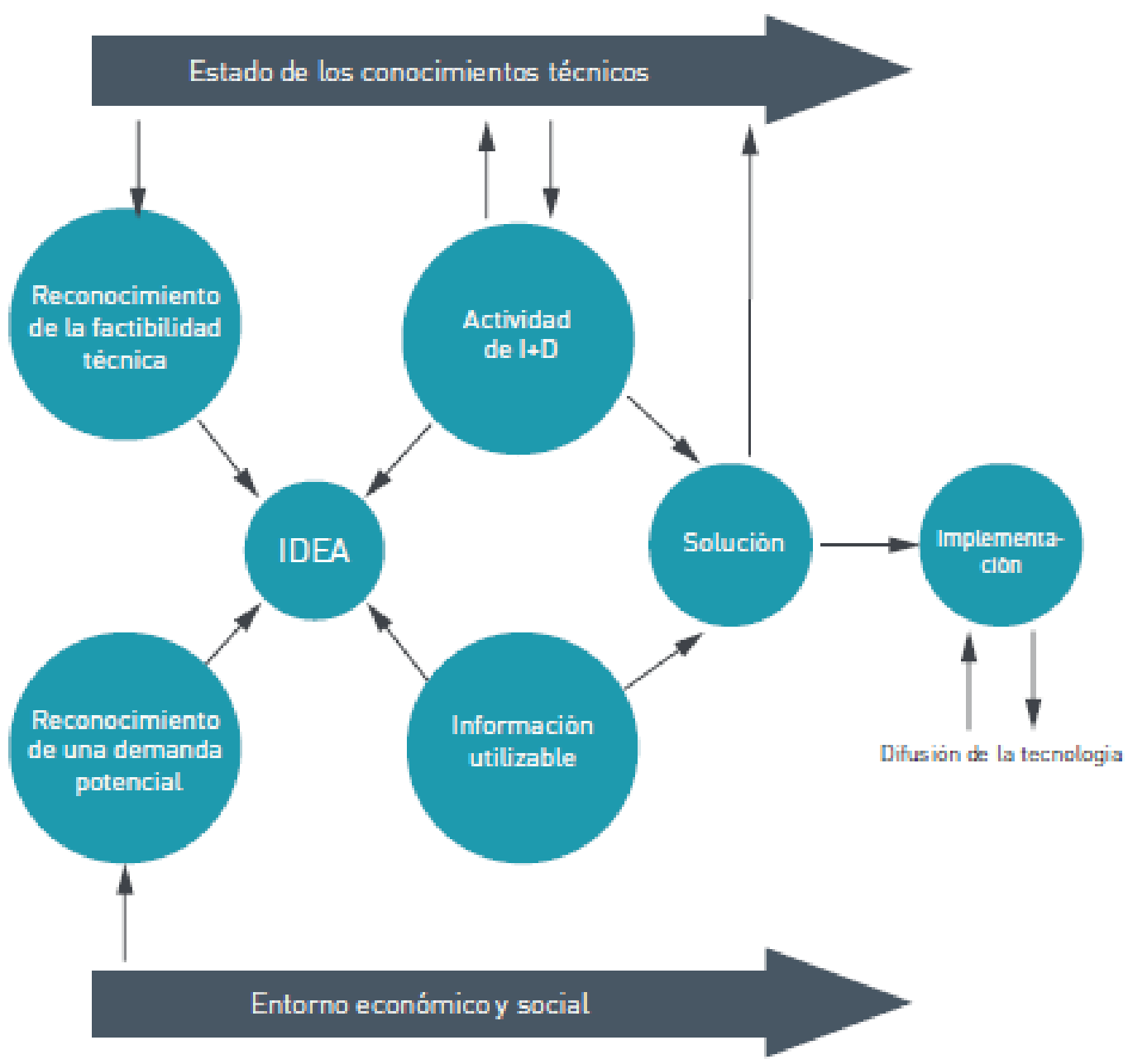

Figura 6. Modelo de Marquis (1969).

\subsection{Estrategia General}

El presente ítem se analizó tomando como punto de partida a la oportunidad de negocio potencial.

En virtud de la información y datos recopilados se destaca la ausencia del plan estratégico, suplida de modo exitoso por el promotor en el desarrollo del proyecto, dada la experiencia, formación académica y convencimiento de éxito de la 
propuesta y el gerenciamiento de factores interactuantes necesarios para el logro (París, 2014). ${ }^{25}$

Se infiere que de modo tácito el promotor del proyecto y cumpliendo su rol de desarrollador y coordinador del mismo, logró unir los puntos entre la idea inicial y la puesta en marcha hasta llegar al funcionamiento productivo y comercial rentable.

De este modo logró para su producto un mercado no competido, del tipo océano azul basado en lograr innovación en valor.

Dicho término más allá de lograr innovación tecnológica en productos y procesos, involucra y alinea tanto la innovación, como la utilidad, el precio y sus posiciones en costos (Cham Kim y Mauborgne, 2005). ${ }^{26}$

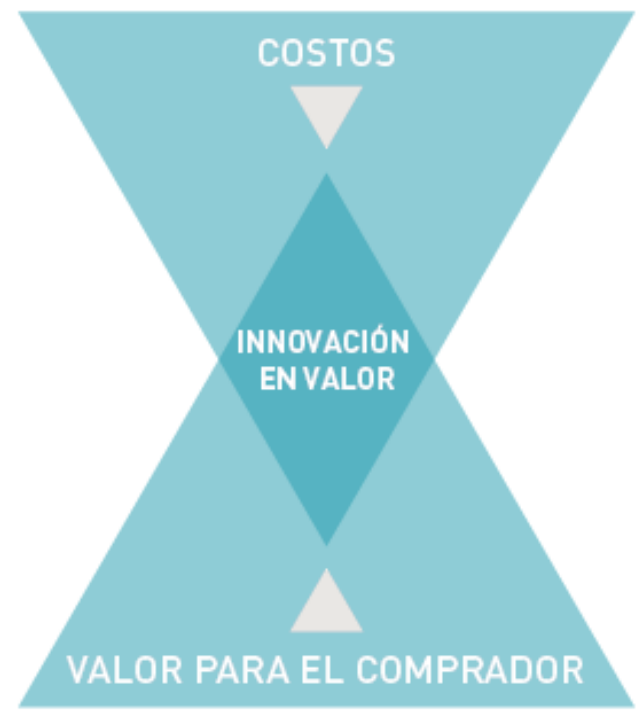

Figura 7. Modelo de estrategia del océano azul (ChamKim y Mauborgne, 2005: p.23).

Se infiere también que de modo tácito cumplió con los conceptos básicos de formular una estrategia de océano azul, dado el logro de un espacio de mercado

\footnotetext{
${ }^{25}$ PARÍS, J. A. (2014). Los cuatro aspectos esenciales por investigar. Poliantea, 10(18), pp. 65-81.

${ }^{26}$ CHAM KIM, W., MAUBORGNE, R. (2005). La Estrategia del Océano Azul. Editorial Norma.
} 
sin competencia, que el mismo provocó una marcada pérdida de relevancia de sus competidores o similares, que creó y capturó nueva demanda, y que logró romper la disyuntiva de valor-costo, direccionando las actividades de la empresa al éxito de vincular justamente la diferenciación del producto nuevo con los bajos costos.

En cuanto a los riesgos atenuados en la etapa de formulación de la antes mencionada estrategia no escrita pero desarrollada, la menor escala en cuanto a lotes de fabricación rentables y su modelo de negocios se destacan como puntos relevantes.

Desde el punto de vista de la ejecución, logró superar obstáculos claves de la organización cómo el desarrollo de proveedores y alianzas estratégicas, disminuyendo así riesgos organizacionales y de gestión.

En cuanto al modelo para la toma de decisiones como otra variable de éxito, tanto en el proyecto como en el funcionamiento actual y diario de la empresa, consistió en un sistema horizontal, donde cada socio cuenta con igual peso y el objetivo primordial es llegar a la unanimidad.

En este análisis retrospectivo se analizó también la empresa tomando como base un cuadro comparativo de ciertos puntos salientes y distintivos de la estrategia general propia versus la de sus competidores.

Esto permitió capturar y entender el esquema de generación de valor de ambos. Se incluyeron en él, tecnología de fabricación, características intrínsecas del producto, características del proceso productivo, presencia en mercados, costos de fabricación y precios. 
Tanto las características diferenciales del producto, como las del proceso productivo y costos se considerarán en el punto estrategia tecnológica.

\subsection{Estrategia de Innovación Tecnológica}

Desde el inicio se tuvo una visión de diseño integrado a la manufactura, generando una innovación incremental en la mejora del proceso productivo de rotomoldeo para lograr competir cuantitativa y cualitativamente con el proceso de inyección.

El diseñador adaptó el proceso productivo modificando principalmente la matricería y eliminando los tiempos muertos de carga y descarga de material en el molde y los ciclos de calentamiento y enfriamiento de los mismos. Por otro lado, los costos de infraestructura y la mano de obra requerida en relación a la inyección son mucho menores.

Este "saber hacer" se transforma en la ventaja competitiva de la empresa y si bien es patentable, se protege mediante el blindaje de la empresa en forma de secreto industrial y se transforma en una barrera de entrada muy alta para sus competidores.

Se lograron producir mensualmente hasta 9.200 unidades en jornadas laborales continuas de 24 horas, logrando una producción nivelada que permitía satisfacer las demandas de los clientes.

Por otro lado, a diferencia de sus otras unidades de negocios (kayak, muñecas, autopartes y objetos industriales especiales), que respondían a una estrategia imitativa, en el caso de las butacas se buscó un posicionamiento como líderes en estándares de calidad y seguridad. 
Los actuales modelos de butacas Babylin que se ofrecen en el mercado, son fabricados con los nuevos estándares de calidad (ahorro energético, cuidado del medio ambiente, preparación para certificar normas ISO y TÜV) y los definimos como productos generacionales de butacas GD-E, que se corresponden con la nueva serie GD (Global Design), ahorro energético en el proceso de fabricación, siendo el sistema que utiliza menos energía en la actualidad.

\subsection{Estrategia de Innovación de Diseño}

\subsubsection{Innovación en forma de nuevo producto y de nuevos affordances ${ }^{27}$}

Se trata en este caso de aspectos ligados a las demandas de los clientes más que a las de los usuarios finales.

En este caso se pensó en un producto apilable, aspecto fundamental para la logística de producción y traslado.

Por otro lado, la empresa ofrecía el servicio complementario de colocación y ofrecía cinco años de garantía, lo cual es un aspecto intangible fundamental para los clientes. La variable de colores que ofrece el proceso productivo, por ejemplo, permitió abarcar diferentes clientes en los cuales los rasgos de pertenencia son claves.

\subsubsection{Mejora en la calidad de uso del producto}

Estos aspectos fueron desarrollados en los requerimientos de diseño que guiaron a la idea, y están estrechamente ligados al usuario final del producto.

\footnotetext{
${ }^{27}$ Affordances: nuevas prestaciones de servicios.
} 
Junto con la mejora en el producto, se buscó la optimización de la instalación de butacas, bajando los tiempos de instalación $40 \%$ del tiempo real.

\subsection{Estrategia corporativa de diseño de marca e isologotipo}

En los últimos cinco años, la marca Babylin sufrió algunas modificaciones en el diseño de su isologotipo (o genéricamente: marca). Para actualizar la imagen corporativa, se contrataron servicios de diseño para el logotipo, con la premisa de comunicar dinamismo y/o movimiento (Dinnie, 2011). ${ }^{28}$

Entre los resultados obtenidos, se destacaron tres versiones, de las cuales dos se aplicaron integralmente a toda la organización y comunicaciones.

Seguidamente, se muestra la evolución del diseño de marca, a través de las tres propuestas más significativas.

Esta primera propuesta de actualización de marca (Figura 8), fue un paso intermedio necesario para iniciar una evolución. Si bien se estudiaron algunas aplicaciones y cambios de color (Figura 9), tuvo algunos inconvenientes para erigirse como nueva identidad de marca empresarial y no llegó a aplicarse.

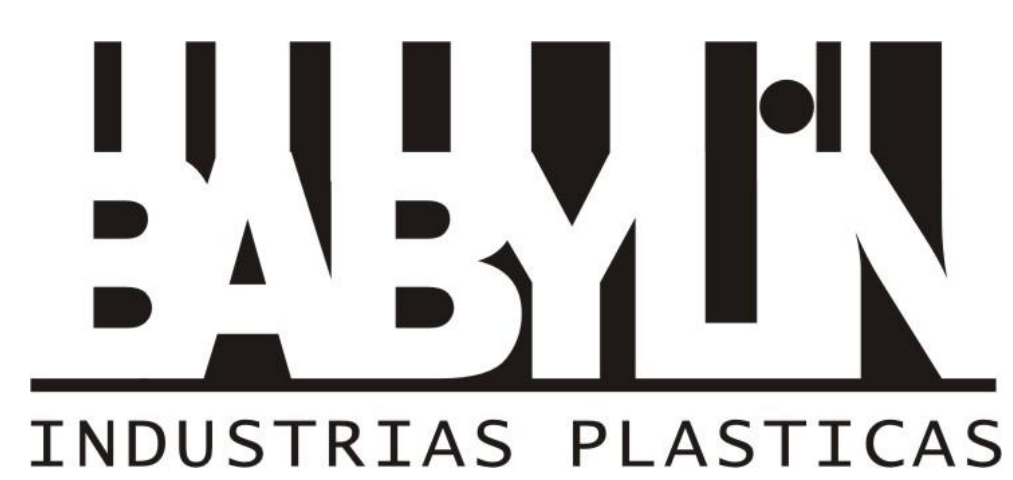

Figura 8. Primera actualización de isologotipo de la empresa Babylin.

${ }^{28}$ DINNIE, K. (2011). City branding: theory and cases. United Kingdom: Palgrave Macmillan. 

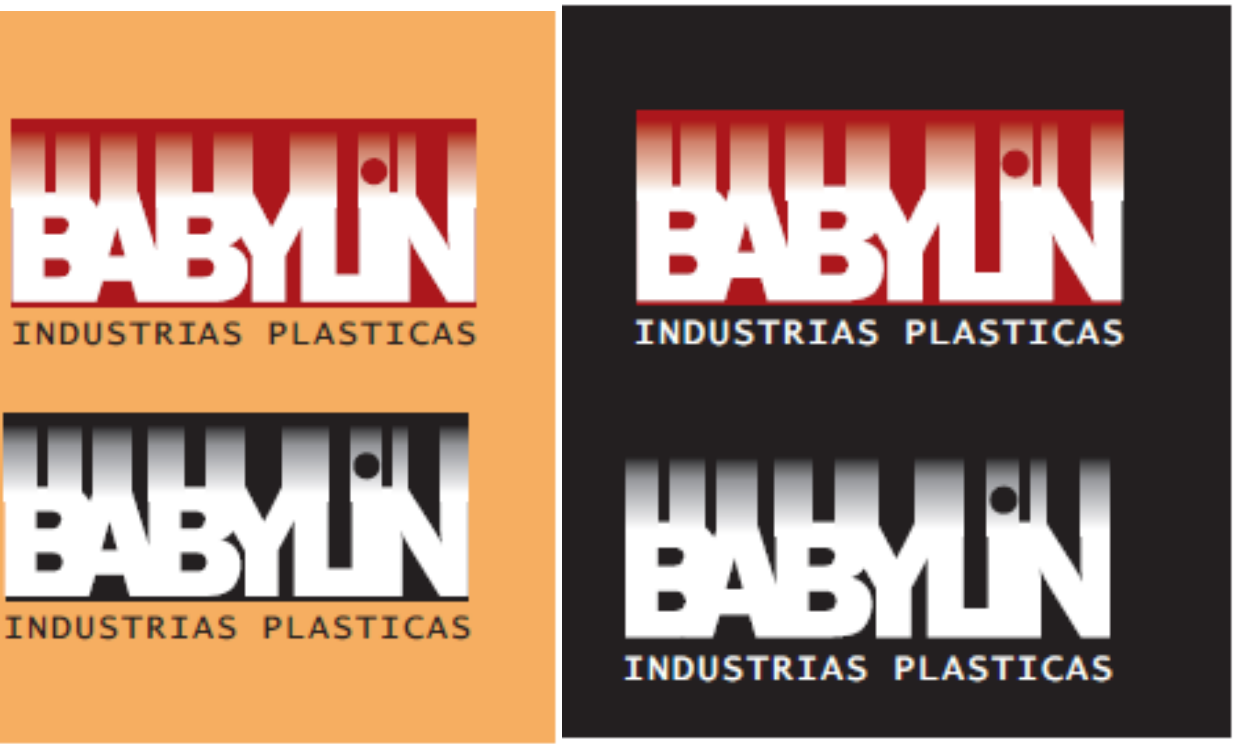

Figura 9. Prueba de color y contraste de la primera actualización de marca.

La segunda actualización del isologotipo (Figura 10) tuvo mayor aceptación al interior de la organización y se utilizó durante un año y llegó a tener un grado medio de difusión (Figura 11).

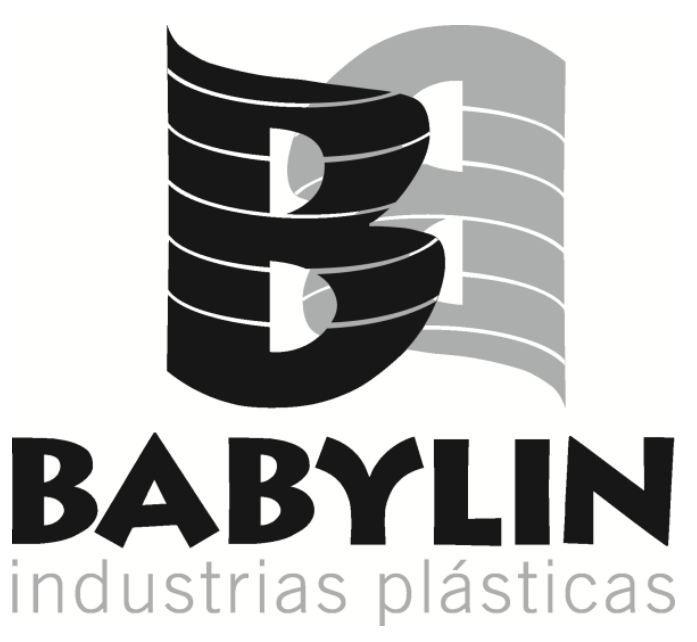

Figura 10. Segunda actualización de isologotipo de la empresa Babylin. 

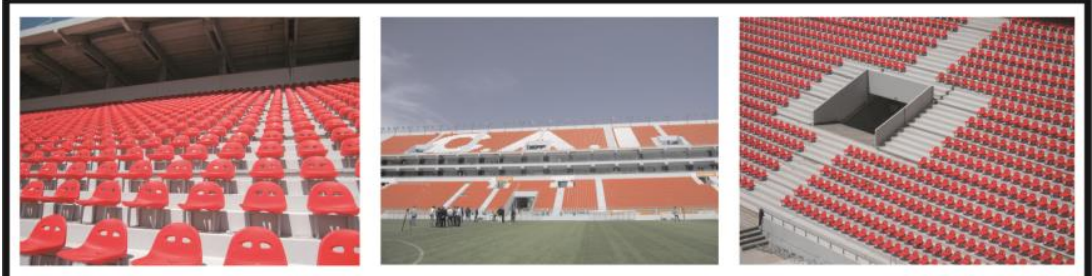

/ Diseño y producción de butacas adaptable a sus necesidades /

/ Excelencia en calidad / Amplia experiencia en el rubro /
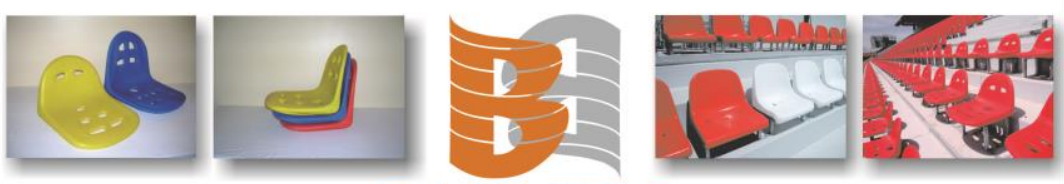

BA B División Equipamientos Deportivos industrias plásticas

Olaguer Feliú 4090 (B 1605BAN) Munro - Pcia. de Bs. As. - Tel. (011) 4761-2843 / Fax 54-11 4761-6730 info@babylinplasticos.com.ar

Figura 11. Publicación realizada en revista especializada de arquitectura.

En la actualidad, la imagen actual de marca de empresa (Figura 12), expresa el sentido de la rotación, movimiento y dinámica -en continuo movimiento- de la empresa. Sintetiza la tecnología clave (Rotomolding) y principal producto de su cartera (Seating), connota la provisión de soluciones a medida (Solutions) y le otorga mayor versatilidad en el uso del nuevo panorama internacional de actuación (Anholt, 2005). ${ }^{29}$
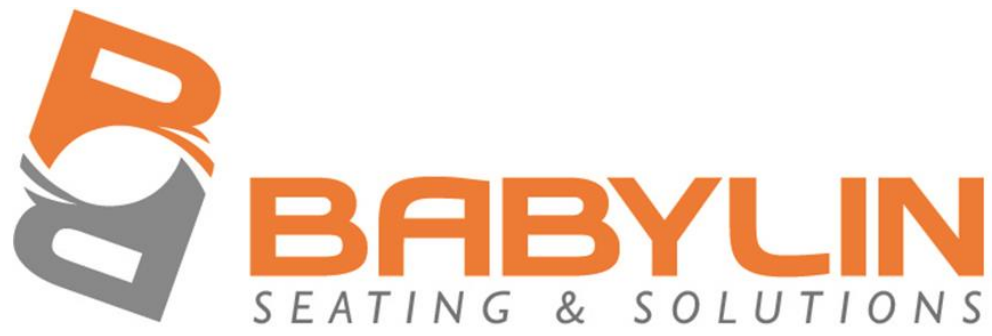

Figura 12. Imagen actual de marca de la empresa Babylin.

${ }^{29}$ ANHOLT, S. (2005). Some important distinctions in place branding. Place Branding and Public Diplomacy, Vol. 1, No. 2, pp. 116-121. 


\subsection{Estrategia CKD de Babylin para el 2020}

Se trata de una iniciativa de diseño de CKD, siglas en inglés de "Completly Knock Down" (Kit de montaje) (Meznar, 2012). ${ }^{30}$

Principalmente, se trata de un sistema logístico mediante el cual se consolidan en un almacén las piezas necesarias para armar la obra y se envían según los programas de fabricación a otros lugares del exterior, donde se ensamblan todos los componentes, montando los mismos en un estadio de cualquier parte del mundo.

La logística CKD, abarca el diseño, la concepción, la planificación del embalaje, el almacenamiento temporal de piezas preembaladas y no preembaladas, la realización de los diferentes pedidos de acuerdo al programa y la disposición de todo el material de embalaje. También el manejo y la disposición de los contenedores, el relleno de protección de la mercancía embalada y la gestión de envases vacíos.

Se trata por tanto de diseñar un "embalaje suficiente", esto es de materiales y dimensiones adecuadas al producto y tratando de optimizar al máximo el medio de transporte para el que están diseñados (rutas, autopistas, marítimos o aéreos). En cuanto a los materiales utilizados, dependerá del tipo de pieza, del medio de transporte y del destino de la misma. Los embalajes que se utilizan pueden ser de cartón, madera o combinaciones entre ambos, o contenedores metálicos (cuando el destino permita el retorno de los mismos). Además se usan múltiples materiales

\footnotetext{
${ }^{30}$ MEZNAR, D. (2012). Transfer of Technology : Technical, Technological and Logistic Approach in the Production and Assembly of Vehicles. Asian Journal of Business and Management Sciences, Vol. 1 No. 11, pp. 85-93.
} 
auxiliares, espumas técnicas, cantoneras, etc., para que la pieza esté perfectamente anclada y llegue en excelentes condiciones a su destino.

En definitiva, en los últimos tiempos, debido fundamentalmente al cambio de orientación en la estrategia de las compañías del sector de grandes obras deportivas hacia sistemas "pulldemand" y a la globalización, se ha puesto un especial énfasis en cómo posicionar con el menor costo y en el menor tiempo posible el producto en manos del consumidor que lo demanda. Dentro de ese costo logístico, aparece el packaging como un factor determinante en la búsqueda de productividades, es asíque todo ello cobra especial relevancia en los embalajes para la exportación para los modelos de logística CKD.

Es así como Babylin posee vocación y capacidad para aportar soluciones personalizadas y específicas a cada uno de susclientes, tanto en sus necesidades existentes como en las de sus desarrollos futuros. Babylin, pone a disposición una amplia gama de productos, analizando y desarrollando todas las posibilidades de obra, soluciones especiales y contemplando las nuevas normativas de cuidado de medio ambiente con el ahorro energético y el menor consumo.

\subsubsection{Beneficios y riesgos}

La logística CKD requiere tener bien definido su alcance, ya que si no está planificado y programado correctamente, se pueden disparar los costos. Con este sistema también se puededeterminar el tamaño de lote óptimo, teniendo en cuenta el volumen de los contenedores y el tipo de cajas a utilizar, con el fin de aprovechar al máximo el volumen en el transporte. 
Además de los beneficios económicos que este sistema trae consigo, se pueden obtener beneficios comerciales bilaterales o desventajas arancelarias, al momento de enviar el producto completamente ensamblado o montado.Sin embargo, al exportar un producto por piezas, las empresas se topan con beneficios en las tasas arancelarias, ya que éstas son más baratas cuando se exportan productos por partes, que cuando se lleva a cabo una exportación con artículos completamente armados (Pau Cos y otros, 1998). ${ }^{31}$

El elemento principal de este tipo de logística es el almacén consolidado en el cual se llevan a cabo todas las funciones de recepción de materiales, embalaje, y envío al país destino. Los embalajes en este tipo de proyecto son esenciales, ya que deben ser diseñados para resistir un largo tiempo de tránsito que puede ser de varias semanas e incluso meses, posiblemente en un ambiente corrosivo y con un gran número de manipulaciones.

\subsection{Comercialización del Producto e Inserción en el Mercado}

La decisión adoptado por el Gobierno de la Provincia de Buenos Aires apuntaba a una butaca acolchada, pero como el Estadio Único de La Plata aún no iba a contar con el techo, finalmente se eligió una butaca que respondiera con los requerimientos de diseño y alta calidad técnica (antivandálica, libre de mantenimiento). Luego de la realización de la preserie de 500 unidades para el Estadio Único Ciudad de La Plata, la Unión Transitoria de Empresa (UTE), encargada de la ejecución, se vio frente a una propuesta totalmente diferente y superadora.

\footnotetext{
${ }^{31}$ PAU COS, J., DE NAVASCUÉS Y GASCA, R., y YUBERO ESTEBAN, M., (1998) Manual de Logística Integral. Editorial Díaz de Santos, Madrid.
} 
Si bien su precio era mayor, el hecho de haber trabajado con una estrategia de diferenciación, dio lugar a ventajas comparativas que dejaron sin posibilidades a los competidores. Además, una estrategia social, diferenció aún más a esta propuesta: la incorporación de la Escuela de Educación Técnica Nº 1 de Ensenada, la cual a través de los alumnos avanzados $\left(5^{\circ}\right.$ y $6^{\circ}$ Año) supervisaron la calidad de las butacas producidas.

El diseñador industrial y docente de los alumnos incorporados a este proyecto ahora contaba con el respaldo de una empresa con experiencia y había logrado la capacidad tecnológica para abastecer a todo el estadio, con lo cual la empresa ganó el concurso de precios y fabricó finalmente para este cliente alrededor de 23.000 butacas.

La difusión de este producto fue inmediata y el estadio servía como un canal de publicidad muy eficiente ya que mostraba el desempeño del producto en situaciones de uso reales.

Fue así como crecieron las ventas de manera exponencial. A nivel nacional los clientes sucesores fueron: Club Atlético Boca Juniors, Club Atlético Independiente de Avellaneda, Club Atlético Huracán, Club Atlético San Lorenzo de Almagro, Instituto de Córdoba, Gimnasia y Esgrima de La Plata, Estudiantes de La Plata entre otros.

Tras casi quince años de su implementación, no han surgido empresas que compitan con esta tecnología en el nicho de mercado, lo cual deja en claro la efectividad de la estrategia adoptada. 
La empresa recibió propuestas para trasladarse a diversos países de Latinoamérica, en los cuales esta tecnología no se encuentra explotada (como es el caso de Perú y Bolivia, por nombrar solo dos).

Se capturaron mercados inexplorados abasteciendo a estadios de Uruguay, Paraguay llevando a cabo procesos de exportación satisfactorios.

Todos estos aspectos cuantitativos, en complemento con la coherencia en el accionar desde el diseñador industrial en el camino entre la idea y la materialización del proyecto actúan de sustento para considerar al caso de estudio como exitoso.

\subsubsection{Usos alternativos en la exploración de nuevos segmentos}

En el desarrollo de nuevos segmentos del mercado, la butaca M1 de Babylin, encontró nuevas aplicaciones en el campo de la náutica sin motor.

Específicamente, se desarrolló un anclaje especial para su utilización en kayak.

Se presenta como el único asiento rígido e irrompible para kayak del mercado, sirve para todos los kayak, puede elegirse del color del kayak, viene incorporado un sistema rápido de anclaje que permite su colocación o extracción en solo diez segundos. Además, incluye todos los elementos de fijación: correa con velcro y tornillo para la base y una correa con ganchos para el respaldar. 


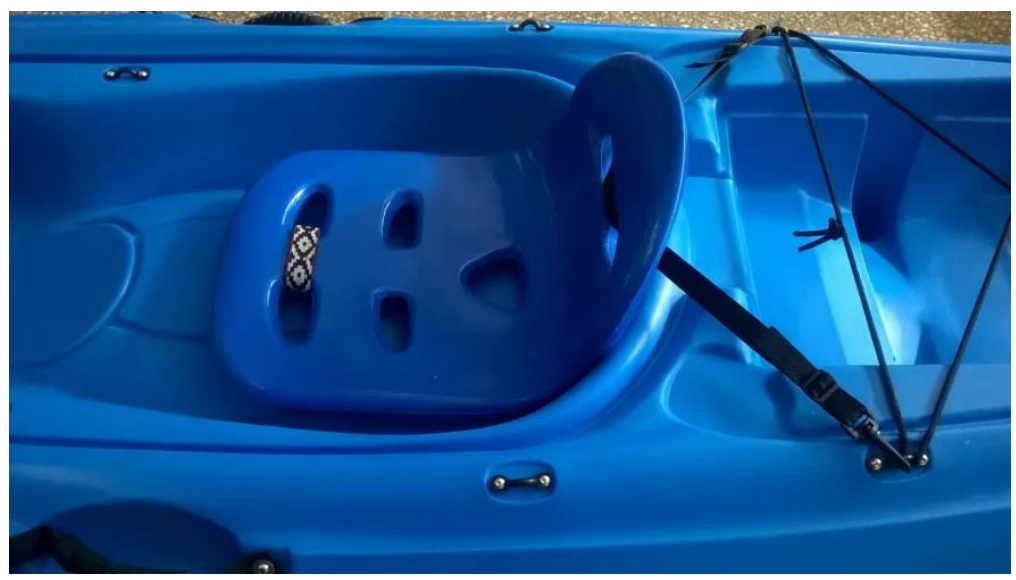

Figura 13. Muestra del M1 y kit de fijación de Babylin aplicado en un kayak.

\subsubsection{El canal de venta electrónico: MercadoLibre}

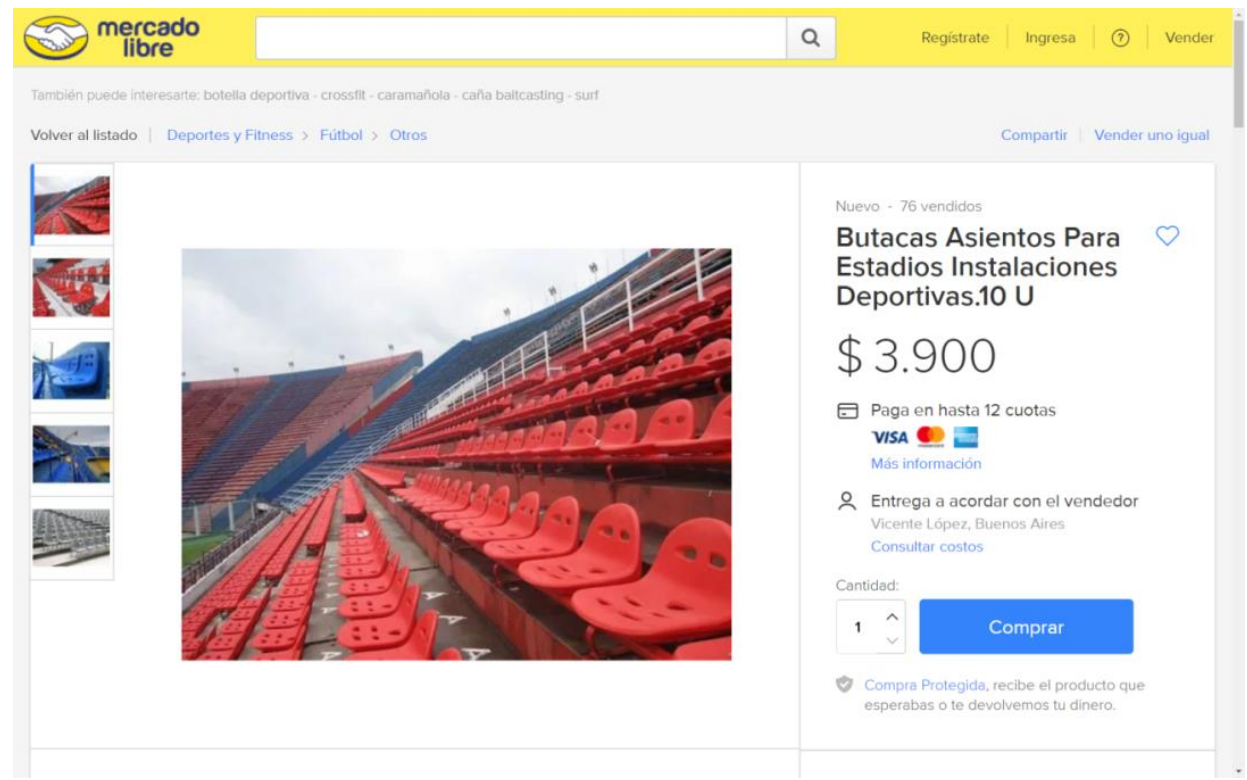

Figura 14. Publicación de M1 de Babylin en Mercado Libre.

Desde 2012, la venta minorista de butacas M1 de Babylin, toma como canal principal de E-Commerce (comercio electrónico) el sitio de MercadoLibre, que le permite obtener un portal actualizado de ventas con imágenes y hacer uso de un canal de comunicación con los compradores y público interesado. 
Además, el mismo sirve de publicidad en web, ya que en los buscadores de internet, aparece muy bien posicionado, siendo en la actualidad el único resultado con imagen de Google Argentina.

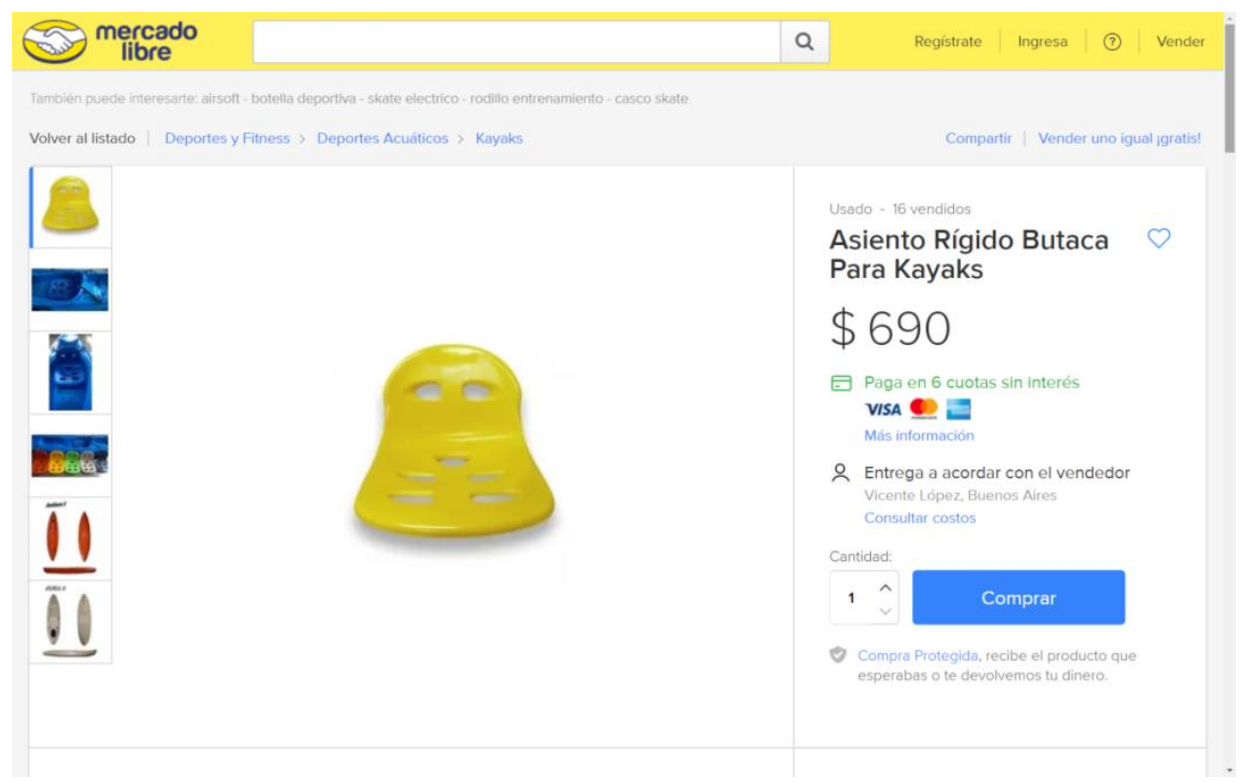

Figura 15. Publicación de M1 de Babylin para kayak en Mercado Libre. 


\section{CAPITULO VI. Conclusiones.}

\section{Análisis de la experiencia y reflexiones finales}

Analizando los diversos modelos de innovación, se puede ver un intento por lograr esquemas totalizadores y generalizables para diferentes contextos y organizaciones.

Sin embargo, se puede inferir en que esto no es posible, ya que excluye la complejidad real que tiene cada problemática de diseño y marketing, y de algún modo idealiza el sistema en el que ocurren estos contextos.

Otro de los aspectos relevantes es el hecho de que los modelos de innovación, son planteados a partir de la idea, y no abarcan la etapa previa de la cual surgen dichos disparadores.

Esto lleva a una reducción binaria del análisis dando lugar a los procesos traccionados por la tecnología (technology-push) y los procesos impulsados por el mercado (market-pull), sin embargo se podría proponer una tercer categoría en la cual el factor que impulsa es el diseño a partir de un análisis-diagnóstico de situación.

Así como un médico puede prever ciertos quiebres en situaciones futuras, el especialista en marketing, también tiene esta capacidad de captar señales débiles de los comportamientos de los futuros usuarios y traducirlo a una hipótesis futura que posteriormente será la base del desarrollo del producto o servicio que dé respuesta a esa conducta colectiva. 
Es decir, se puede pensar que el mercado actúa de manera pasiva, y de algún modo el gestor de marketing detecta los espacios inexplorados que generan nuevas demandas.

Es interesante poner en relevancia, que a diferencia de los productos del denominado diseño de autor que generalmente están destinados a un público exclusivo y muchas veces tienen una baja complejidad tecnológica, el caso de estudio abordado es un claro ejemplo de diseño anónimo.

Se trata de un producto de uso colectivo, producido en serie y que requirió un esfuerzo tecnológico considerable.

En suma, el diseño y el marketing debe enfrentarse a esta paradoja en la cual, los productos que generan un gran impacto en las formas de uso de las personas, no son asociados a la disciplina proyectual que les dio origen, mientras que los productos de autor construyen semánticamente a fuerza de publicidad y fantasía el imaginario colectivo de la palabra diseño.

En respuesta al análisis retrospectivo realizado se describen a continuación las conclusiones que pueden inferirse como relevantes para el éxito de la gestión de la innovación tecnológica realizada, entendiendo dicho éxito como el funcionamiento rentable de una empresa una vez terminado el desarrollo e implementación del proyecto en cuestión.

En primer medida y como punto destacado se considera al diseñador industrial especialista en marketing internacional cómo factor crítico de éxito, dado que su formación académica y rol profesional permitió ante la visión de una oportunidad de negocios, integrar en un proyecto una idea inicial determinada, las necesidades, intereses y gustos de un cliente potencial y las capacidades 
tecnológicas disponibles para llevarlo a cabo de modo rentable en el entorno socioeconómico y político del momento.

La estrategia tecnológica fue el componente inicial y relevante de éxito como parte de la estrategia general de la empresa, ya que permitió tanto utilizar un proceso industrial existente en otro tipo de productos, como así también la adaptación necesaria a los requerimientos de costos y el punto de equilibrio del proyecto en cuestión.

La gestión de la innovación llevada a cabo provocó una consecuente innovación tecnológica incremental en el proceso industrial, permitiendo reducir sensiblemente tiempos y costos negativos en el cash-flow acumulado del proyecto hasta llegar a su punto de equilibrio.

La elección de la estrategia tecnológica y el proceso industrial asociado, como consecuencia de haber definido inicialmente y de modo no escrito los valores de "calidad" y "seguridad ante actos vandálicos", sumado también a la decisión de trabajar bajo estándares de calidad del rubro juguetes, acotaron el perfil tipo del fabricante y tiempo de búsqueda del mismo como socio estratégico indispensable para el desarrollo del proyecto.

Retrospectivamente y pese a no contar con un documento escrito de la estrategia general desarrollada y su plan estratégico, se infiere que en el proyecto se empleó una estrategia del tipo "océano azul", ya que cumplió con el precepto de desarrollar innovación en valor, asociando la creación de valor percibida por el cliente con una estructura de costos menor.

La gestión de la innovación desarrollada tanto en el proyecto como en la empresa hoy en funcionamiento otorgó fortaleza al modelo de negocios empleado, 
permitiendo que la propuesta de valor cuente con una fuerte barrera distintiva frente a la competencia tanto en sus características intrínsecas como en la relación del punto de equilibrio por la masa crítica rentable fabricada. Esto impidió ser descartado en licitaciones bajo prácticas no transparentes.

La gestión de innovación tecnológica bajo estudio, tanto en producto como en proceso, provocó consecuentemente mejoras en la calidad de gestión y productos de proveedores.

Finalmente y por fuera de los límites de la gestión de la innovación tecnológica, el presente caso es una muestra también de innovación en la gestión de modelo de negocios.

El desarrollo de un tipo de sociedad particular y el sistema de toma de decisiones y resolución de conflictos empleado son una muestra acabada de ello.

Como corolario, se destaca queel aspecto explicativo del éxito del proyecto, radica en la formación académica de grado y postgrado del gestor del mismo. 


\section{Referencias Bibliográficas:}

ANHOLT, S. (2005). Some important distinction sin place branding. Place Branding and Public Diplomacy, Vol. 1, No. 2, pp. 116-121.

BONSIEPE, G. (2010). El Diseño en Tiempos de Turbulencias. Primer Congreso Internacional de Diseño e Innovación de Cataluña.

CHAM KIM, W., MAUBORGNE, R. (2005). La Estrategia del Océano Azul. Editorial Norma.

CHIAPPONI, M. (1999). Cultura Social del Producto. Editorial Infinito.

DINNIE, K. (2011). City branding: theory and cases. United Kingdom: Palgrave Macmillan.

LEIRO, R. (2006). Diseño, Estrategia y Gestión. Ediciones Infinito.

LITTLE, A. D. (1981). The Strategic Management of Technology. Cambridge, Massachusetts.

MARQUIS, D.G. (1969). The Anatomy of Successful Innovations. National Science Foundation, Technical Report, Vol. 69.

MEZNAR, D. (2012). Transfer of Tehnology : Technical, Technological and Logistic Approach in the Production and Assembly of Vehicles. Asian Journal of Business and Management Sciences, Vol. 1 No. 11, pp. 85-93.

PARÍS, J. A. (2009). Marketing esencial,un enfoque latinoamericano. Errepar, Buenos Aires.

PARÍS, J. A. (2014). Los cuatro aspectos esenciales por investigar. Poliantea, 10(18), pp. 65-81.

PAU COS, J., DE NAVASCUÉS Y GASCA, R., y YUBERO ESTEBAN, M., (1998) Manual de Logística Integral. Editorial Díaz de Santos, Madrid.

PLANELLAS, M., MUNNI, A. (2015). Las Decisiones Estratégicas. Los 30 modelos más Útiles. Editorial Conecta. 
ROTHWELL, R. (1994). Towards the Fifth-generation Innovation Process.

International Marketing Review, Vol. 11 Issue 1, pp.7-31.

STRATEGOR (1988). Stratégie, Structure, Décision, Identité Ed. Interdictions.

Fuentes y referencias de Internet:

ASOCIACION DEL FUTBOL ARGENTINO (AFA). Sitio Web: http://www.afa.org.ar ATOMPLAST. Sitio Web: http://www.atomplast.com.ar/

ESTADIOS DE ARGENTINA. Sitio Web: http://www.estadiosdeargentina.com.ar

FIGUERAS. Sitio Web: http://www.figueras.com/es/

RASSEGNA. Sitio Web: http://www.rassegna.com.ar/productos/

VENELLI SEATTING. Sitio Web: http://www.venelliseating.com

WENCO. Sitio Web: http://wenco.com.ar/ 
« Declaro bajo juramento que esta tesis fue elaborada por mi, que no utilicé ningún otro material que no haya dado a conocer en las referencias y que no utilicé frases o párrafos de otros autores, que este trabajo de tesis nunca ha sido presentado ante un comité de evaluación de tesis y que no trasgreda derechos de terceros. » 